\title{
Actions, Adjuncts, and Agency
}

\author{
PAUL M. PIETROSKI
}

\begin{abstract}
The event analysis of action sentences seems to be at odds with plausible (Davidsonian) views about how to count actions. If Booth pulled a certain trigger, and thereby shot Lincoln, there is good reason for identifying Booth's action of pulling the trigger with his action of shooting Lincoln; but given truth conditions of certain sentences involving adjuncts, the event analysis requires that the pulling and the shooting be distinct events. So I propose that event sortals like "shooting" and "pulling" are true of complex events that have actions (and various effects of actions) as parts. Combining this view with some facts about so-called causative verbs, I then argue that paradigmatic actions are best viewed as tryings, where tryings are taken to be intentionally characterized events that typically cause peripheral bodily motions. The proposal turns on a certain conception of what it is to be the Agent of an event; and I conclude by elaborating this conception in the context of some recent discussions about the relation of thematic roles to grammatical categories.
\end{abstract}

Davidson's event analysis leads to a puzzle, resolution of which has ramifications for what actions are.

Like many others, I adopt Davidson's (1967) account of entailments like those among:

(1) Booth shot Lincoln.

(2) Booth shot Lincoln with a pistol.

(3) Booth shot Lincoln on April 13, 1865.

(4) Booth shot Lincoln with a pistol on April 13, 1865.

Sentence (4) entails (2) and (3), both of which entail (1). These facts demand explanation. For simplicity, ignore considerations of tense. Let us also ignore compositionality within adjunct phrases like "with a pistol", and represent such phrases in our metalanguage with unanalyzed predicates like "With-a-pistol". Then according to Davidson, the logical forms of (1-4) are:

(1a) $\exists e[\operatorname{Shoot}(e$, Booth, Lincoln $)]$

(2a) $\exists e[\operatorname{Shoot}(e$, Booth, Lincoln) \& With-a-pistol $(e)]$

(3a) $\exists e[\operatorname{Shoot}(e$, Booth, Lincoln) \& On-April-13-1865(e)]

(4a) $\exists e[\operatorname{Shoot}(e$, Booth, Lincoln) \& With-a-pistol(e) \& On-April-13$1865(e)]$. 
The inference from (2) to (1) is thus represented as an instance of the valid inference form, " $\exists x(\Phi x a b \& \Psi x)$, so $\exists x(\Phi x a b)$ "; and similarly, mutatis mutandis, for the other entailments. Given that Booth shot Lincoln exactly once, a single event is the truth-maker for (1-4), and this event satisfies the adjunct phrases in (2-4). That is, the truth-maker for (1-4) has the properties specified by "with a pistol" and "on April 13, 1865". The same reasoning applies to:

(5) Booth pulled the trigger.

(6) Booth pulled the trigger with his finger.

(7) Booth pulled the trigger on April 13, 1865.

(8) Booth pulled the trigger with his finger on April 13, 1865.

According to the event analysis, the logical forms of (5-8) are:

(5a) $\exists e[$ Pull $(e$, Booth, the trigger $)]$

(6a) $\exists e[$ Pull $(e$, Booth, the trigger) \& With-his-finger( $e$ )]

(7a) $\exists e[$ Pull $(e$, Booth, the trigger) \& On-April-13-1865(e)]

(8a) $\exists e[$ Pull $(e$, Booth, the trigger) \& With-his-finger(e) \& On-April13-1865(e)].

But while this nicely explains the relevant entailments, it also presents something of a quandary.

Assume that Booth pulled the trigger of the pistol in question exactly once. Then a single event is the truth-maker for (5-8). This event satisfies the adjunct phrases "with his finger" and "on April 13, 1865". But Booth did not pull the trigger with a pistol. That is,

(9) $\neg \exists e[\operatorname{Pull}(e$, Booth, the trigger) \& With-a-pistol $(e)]$.

So the event that makes (5-8) true does not satisfy "with a pistol"; but the event that makes (1-4) true does satisfy this adjunct phrase. Hence, the event that makes (5-8) true is not the event that makes (1-4) true. Similarly, Booth did not shoot Lincoln with his finger. That is,

(10) $\neg \exists e[\operatorname{Shoot}(e$, Booth, Lincoln) \& With-his-finger $(e)]$.

So the event that makes (1-4) true does not satisfy "with his finger"; but the event that makes (5-8) true does satisfy this adjunct phrase. Hence, the event that makes (1-4) true is not the event that makes (5-8) true. As expressed in the metalanguage, the one event is With-a-pistol, the other is With-his-finger. This is rather puzzling, especially for those of us who (following Davidson 1967, 1971) take actions to be events that can be described in many ways. One might have thought that "Booth's shooting of Lincoln" and "Booth's pulling of the trigger" describe a single action. But it is hard to see how these nominalizations of (1) and (5) could be 
descriptions of the same event, if (1) and (5) have different events as their truth-makers. ${ }^{1}$

In this paper, I show how Davidsonians can maintain that the action of Booth's shooting Lincoln is the action of Booth's pulling the trigger, even though the shooting and the pulling are distinct events. The proposal will shed light on much discussed sentences like:

(11) Booth killed Lincoln on April 13, but Lincoln did not die until April 14.

More interestingly, the proposal bears on entailments like

(12) Nora melted $\mathrm{T}_{\mathrm{T}}$ the chocolate, so the chocolate melted where the subscripts indicate transitive and intransitive forms of the verb. I argue that this semantic investigation tells us something about the nature of actions: it supports Hornsby's (1980) claim that actions are causes of bodily motions. I conclude that the best way to preserve the event analysis, and the associated claim that (nominalizations of) different action sentences can be used to describe a single event, is by identifying actions with what Hornsby calls tryings. (See also O'Shaughnessy 1973, 1980.)

\section{Pieces of the puzzle}

To repeat: there is good reason for adopting the event analysis, which requires that events like shootings be distinct from events like pullings; but, like Davidson, one might well want to identify Booth's action of shooting Lincoln with Booth's action of pulling the trigger; and one might have hoped that the semantics of action sentences would make such identity claims more plausible. Before arguing that Davidsonians can have and eat their cake, I want to describe this tension in a little more detail, by elaborating the event analysis and pointing to some independent sources of what might be called identificationist and anti-identificationist intuitions.

${ }^{1}$ Taylor (1984) discusses this kind of case; see note 4 below. I reserve "action" for particular events, not things potentially done by different people at different times and places. I also ignore gerund phrases used (not as event descriptions, but) in a propositional sense: in "the tolling of the bell" surprised Tom, the italicized phrase can be roughly synonymous with (and as opaque as) "that the bell tolled". (See Vendler 1967, Bennett 1988.) When a so-called perfect event nominal like "the destruction" is in common use, however, the corresponding imperfect nomimal ("the destroying") sounds odd. 


\section{1}

Evidence for the event analysis is not limited to entailments like those in (1-8). Parsons (1990) amasses a body of further data, some of which I summarize here. Davidson's account lets us say that

(13) Nora left before Nick's arrival

is true if and only if an event of Nora's leaving occurred before the event that was Nick's arrival. Davidsonians can also account for the validity of arguments like: whenever Nora cuts onions, she sneezes; Nora cut onions; so she sneezed. For if there is a sneezing (by Nora) whenever there is a cutting (of onions by Nora), and there was a cutting, then there was a sneezing. The event analysis also suggests an attractive treatment of perceptual idioms like

(14) Nora heard Fido bark.

Sentence (14) differs from the propositional attitude report "Nora heard that Fido barked"; in (14), "bark" is untensed, and substituting coreferential expressions for "Fido" seems to preserve truth. So following Higginbotham (1983) and Vlach (1983), one might well take the logical form of (14) to be

(14a) $\exists e \exists f[$ Hear $(e$, Nora, $f) \& \operatorname{Bark}(f$, Fido $)]$.

That is, there is a hearing by Nora of a barking by Fido. Moreover, we can explain the ambiguity of

(15) Nora heard Fido bark in her apartment

if "in her apartment" can modify the hearing or the barking, as indicated in:

(15a) $\exists e \exists f[\operatorname{Hear}(e$, Nora, $f) \& \operatorname{Bark}(f$, Fido) \& In-her-apartment $(e l f)]$

where either reading entails the corresponding reading of "Nora heard something in her apartment".

In the last paragraph, I gave a natural gloss of Davidson's notation: " $\exists e[\operatorname{Shoot}(e$, Booth, Lincoln $)]$ " means that there is a shooting of Lincoln by Booth; and in general, " $\exists x[\Phi(e, x, y)]$ " means that there is a $\Phi$-ing of $y$ by $x$, where $\Phi$-ings are events of a certain sort. This suggests an elaboration of Davidson's hypothesis about logical form in terms of thematic roles, where " $\exists e[\operatorname{Shoot}(e, x, y)]$ " is taken to have further structure: $\exists e[\operatorname{Shooting}(e) \& \operatorname{Agent}(e, x) \& \operatorname{Patient}(e, y)]$; there is an event such that it is a shooting, $x$ is its Agent, and $y$ is its Patient. Intuitively, the Agent of an event is its (salient) initiater; the Patient of an event is the person or thing (saliently) affected. Appeals to thematic structure have proven fruitful, not just in semantics, but in linguistic theory more generally. ${ }^{2}$ So I will

\footnotetext{
${ }^{2}$ See Haegeman (1994) for an overview. Parsons (1990), Schein (1993), and Herburger (1997) offer explicit arguments in favor of thematic decomposition. I capitalize "Agent" and "Patient" to remind us that these are technical notions of the metalanguage.
} 
take this development of the basic event analysis as given, returning in the final section to questions about how thematic categories are related to grammatical categories like "subject" and "object".

By itself, appealing to thematic roles does not solve our puzzle. If anything, the difficulty for Davidsonians is sharpened if we gloss "Booth shot Lincoln" and "Booth pulled the trigger" as:

(16) $\exists e[\operatorname{Shooting}(e) \& \operatorname{Agent}(e$, Booth $) \& \operatorname{Patient}(e$, Lincoln $)]$

(17) $\exists e[\operatorname{Pulling}(e) \& \operatorname{Agent}(e, \operatorname{Booth}) \& \operatorname{Patient}(e$, the trigger $)]$.

For even without considering adjuncts, one might want to distinguish the shooting from the pulling, on the grounds that these events have different Patients. If this was the only reason for denying that Booth's shooting was his pulling, one might view thematic elaboration as unfriendly to Davidson's original proposal. (Moreover, "thematic individuation" of events leads to difficulties that I want to avoid here. See Schein 1993, pp. 94-6.) In any case, the arguments based on adjuncts are still available; and these reasons for distinguishing the shooting from the pulling are untouched by appeal to thematic roles.

None the less, I will argue that we can begin to see how the action of Booth's shooting Lincoln can be the action of Booth's pulling the trigger, by getting clear about what it is to be the Agent of an event. One might, however, deny that there is any puzzle here to resolve. For one might think that the semantic arguments simply refute Davidsonian identity claims about actions, or that Davidson has already offered a reply to such arguments. So let me say briefly why I think otherwise.

\section{2}

An anti-identificationist will grant that no shooting is identical with a trigger-pulling, and conclude that Booth's action of shooting Lincoln was not his action of pulling the trigger. But at least some anti-identificationists will not see this as a cost of adopting the event analysis. For one need not appeal to explicitly semantic considerations in arguing that shootings are distinct from trigger-pullings; such events apparently have different spatiotemporal properties.

Intuitively, the shooting of Lincoln was not over until the bullet entered Lincoln; whereas the pulling of the trigger was over before the bullet left the gun. ${ }^{3}$ Correspondingly, the shooting seems to have parts (involving the

\footnotetext{
${ }^{3}$ An event seems to be measured by its Patient, in that the event extends until its Patient has been saliently affected. I am, however, simplifying matters. The pulling may have continued on (because of "follow-through") after the bullet left the gun; but these parts of the pulling would have occurred too late to have any causal effect on the bullet (or Lincoln).
} 
motion of a bullet) that the pulling lacks. These intuitions become even clearer if we focus on the following contrast:

(11) Booth killed Lincoln on April 13, but

Lincoln did not die until April 14.

(18) Booth shot Lincoln on April 13, but

Lincoln did not die until April 14.

Sentence (11) is anomolous in a way that (18) is not. This suggests, as Thomson (1971) and others have noted, that a killing of $y$ is not over until $y$ dies. Similarly, while Booth shot Lincoln in Ford's Theater, Lincoln died in a boarding house across the street. So it seems wrong to say that Booth killed Lincoln in Ford's Theater. According to anti-identificationists, it is wrong to say this, because the killing and the shooting are distinct events. Once this is granted, there is little reason to deny that the shooting and the pulling are distinct events. Anyone impressed by this line of thought will be unsurprised, if semantic arguments lead to the same conclusion. Far from presenting a puzzle, one might say, such arguments just add to an already strong case for rejecting Davidsonian identity claims about actions. No one action was: Booth's pulling of the trigger; his shooting of Lincoln; the killing of Lincoln; etc.

While this position is not without merits, it fails to engage with identificationist intuitions. If one asks how Booth's action of killing Lincoln could have occurred on the day before Lincoln died, in a theater that Lincoln left while still alive, Davidsonians will reply that Booth did his bit on April 13 in Ford's Theater. Anything that happened after Booth did his bit is at most an effect of his action. Lincoln would have died just the same, had Booth died immediately after firing the pistol. Once he pulled the trigger, Booth needed to do nothing else to kill Lincoln; at that point, it was just a matter of waiting for nature to take its course. Correspondingly, it seems wrong to say that Booth pulled the trigger and shot Lincoln, if this is to mention distinct actions that Booth performed on the fateful day. Using different terminology, one might mark off a special subclass of a person's actions as basic, and say that internalists/identificationists focus on basic actions. Thus, one might allow that non-basic actions can have parts external to actors. I think this way of speaking underplays the importance of the distinction between actions and their effects, while gratuitously increasing the number of actions. But in any case, I assume that Lincoln died from his gunshot wound in the normal way, and without further contribution by Booth (or a malevolent doctor).

Davidson (1971) presses such considerations, thereby supporting an attractive view: actions are changes in persons; and a person's actions are in his control, in a way that effects of his actions are not, since which effects actions have is "up to nature". I think we abandon this internalist 
conception of action at our peril. For the notion of action that interests us in the philosophy of thought is a notion that tracks the contribution of persons to the causal order. It is practically definitional that our actions are the events that constitute our contributions to history. Actions are the points at which we persons make changes in a world that otherwise carries on nicely without us. A person is responsible for the effects of her actions; but this presupposes a distinction between actions and their effects. Intuitively, the effects of my actions are those events I bring about "with the help of nature"- that is, via forces and facts beyond my control. When I throw a stone, I do my bit; I move my body in a certain way. But $I$ am not implicated in the stone's motion through space. The stone's trajectory would have been the same had I ceased to exist once the stone left my hand. (Similarly, as Dretske (1988) notes, even a kicker has done his bit before leg meets ball; leg travels through space awhile after being launched.)

From this perspective, anti-identificationists focus on effects of actions, like Lincoln's death. Given the internalist conception, a single action is at issue when we speak of the killing, the shooting, and the pulling. This raises two questions: how far back is Booth's contribution to the causal order; and can one draw a nonarbitrary line between an action and its effects? Before turning to these matters, though, let us be clear that we do face a puzzle. Spatiotemporal and semantic considerations make it hard to see how the (deeply intuitive) internalist conception of action can be correct. So we should look for assumptions that make it seem that the internalist conception conflicts with anti-identificationist intuitions and the event analysis.

\section{3}

One might think the puzzle stems from a general feature of predication, and thus poses no special problem for Davidsonians, given examples like

(19) Nora swam the channel quickly.

(20) Nora crossed the channel slowly.

If Nora crossed the channel by swimming it in record time, (19) is true. And arguably, (20) is true, since even a record swim would be much slower than typical ways of crossing the channel. According to the event analysis (without thematic elaboration), the logical forms of (19-20) are:

(19a) $\exists e[\operatorname{Swim}(e$, Nora, the channel) \& Quick $(e)]$

(20a) $\exists e[\operatorname{Cross}(e$, Nora, the channel) \& Slow $(e)]$.

It would be a mistake to argue that (19-20) have distinct truth-makers, or that Nora's swimming was not her crossing, on the grounds that the swimming was quick while the crossing was slow. For as Davidson (1967) notes, a parallel argument based on adjectival modification is clearly 
unsound. Something can be a big ant and a small animal; it can be big for an ant, yet small for an animal. This tells us something about the semantics of attributive (or comparative) adjectives like "big". A plausible view is that, relative to context $\mathrm{C}$, "big" is true of things that are big form a $\Phi$, where $\Phi$ is a comparison class determined in $\mathrm{C}$, and $\mathrm{C}$ includes the fact that "big" modifies a particular word, like "ant" or "animal". But this does not tell against identifying the big ant with the small animal. That would leave one creature too many.

Davidson does not apply this paradigm to the cases we have been considering. Still, one might say that: an event can be With-a-pistol for a shooting, yet not be With-a-pistol for a pulling; while the same event is With-his-finger for a pulling, yet not With-his-finger for a shooting. But extending the "big"/"small" analogy to "with a pistol" and "with his finger" feels strained, even if "quick" and "slow" are themselves attributive modifiers (see Taylor 1984, pp. 25-6). And the claim that every adjunct phrase is comparative seems gratuitous. I see no reason to say that an event can be On-Monday for a swimming, yet not On-Monday for a crossing. So at a minimum, anyone adopting this kind of response owes a principled account of how (and how far) to extend the analogy with attributive adjectives. ${ }^{4}$

\section{Grounding complex events}

The proper response to the puzzle presumably lies in the fact that actions have a concertina of effects, and that we typically refer to an action in part by referring to one of its effects (see Feinberg 1965). The question is how to turn this familiar observation into a proposal that preserves the internalist conception of action, while granting that shootings are distinct from pullings. Stated abstractly, my suggestion is simple: characterize "Agent"

\footnotetext{
${ }^{4}$ Moreover, if all adjunct phrases are like "big”/“small”, one cannot ever argue against proposed event identities by using the event analysis in conjunction with intuitions about the truth conditions of sentences involving adjuncts. (It would be strange for Davidsonians to thus sever metaphysical and semantic issues.) Taylor also mentions two other examples, due to David Wiggins and John Foster. Nora's action of walking uphill can be her action of signalling that the coast is clear. Yet the walking is uphill, while the signalling is not; and it hardly helps to say an event can be uphill for a walking without being uphill for a signalling. If a pool player sinks the 7 and the 9 on the same shot, his action is at once a sinking of the 7 and a sinking of the 9. But the sinkings have different properties; and here, it is not even clear how to apply the response considered in the text. Parsons (1990) offers yet another kind of example: if Nora pays the bill with a cheque, her paying (of the bill) is With-a-cheque, but her writing (of the cheque) is not; yet in the circumstances, one might want to identify the action of paying with the action of writing.
} 
so that identificationist and anti-identificationist intuitions have a place in the (thematically elaborated) event analysis.

\section{1}

A common anti-identificationist thought is that some events are parts of others (see Thomson 1977). Consider the toppling of a line of dominoes. This event has parts; and some of its parts (the topplings of individual dominoes) are caused by other parts. One can speak here of a process; but taking processes to be complex events will simplify matters. Say that event $D$ grounds event $E$, if: $D$ and $E$ occur; $D$ is a (perhaps improper) part of $E$; and $D$ causes every event that is a proper part of $E$ but is not a part of $D$. Every event grounds itself. But more interestingly, the toppling of the first domino grounds the complex event that is the toppling of the whole line of dominoes. ${ }^{5}$

Suppose Booth's pulling of the trigger and his shooting of Lincoln are distinct complex events: only the shooting has parts that begin after the trigger has gone back. This is not to deny that the complex events overlap, or that a single event grounds both. But speaking of parts is a natural way of getting at the idea that a shooting of Lincoln (unlike a trigger-pulling) involves a projectile traversing space and entering Lincoln. One can accommodate anti-identificationist intuitions by saying that action sentences quantify over complex events. Consider:

(21) $\exists e[\operatorname{Shooting}(e) \& \operatorname{Agent}(e$, Booth $) \& \operatorname{Patient}(e$, Lincoln $) \&$ With-a-pistol $(e)]$

(22) $\exists e[$ Pulling $(e) \& \operatorname{Agent}(e$, Booth $) \& \operatorname{Patient}(e$, the trigger $) \&$ With-a-pistol $(e)]$.

If the domain of quantification includes grounded complex events, the shooting and the pulling can be distinct events. Thus, the shooting can be With-a-pistol while the pulling is not. So (21) can be true while (22) is false. This leaves many details to be worked out. For example, specifying the notion of instrumentality expressed by "with" is hard. (Perhaps the shooting is With-his-finger, relative to a context in which someone had bet that Booth would fire the pistol without using his finger. But in my view, this would show that the semantic contribution of "with" is context sensitive, not that the shooting is With-his-finger relative to every context.) But it is plausible that an account along these lines can capture the sense in which the shooting differs from the pulling. The trick is to see how, given

${ }^{5} \mathrm{I}$ am not saying that for every event $D$, there is another event $E$ consisting of $D$ and some of its effects. The grounded event must occur (exist). But some events are grounded by others, and I think we have sortal terms for such events: "pulling", "shooting", etc. It may be that a weaker relation than grounding would serve my purposes equally well, while covering more cases; if so, I would welcome modification of what follows in terms of the weaker relation. 
such an account, Booth's action of pulling the trigger can still be his action of shooting Lincoln.

\section{2}

This is where appeal to thematic roles comes in. Suppose the following thesis is roughly correct: $\operatorname{Agent}(e, N) \leftrightarrow \exists a$ [grounds $(a, e) \&$ action $(a, N)]$; $N$ is the Agent of event $e$, just when $e$ is grounded by an action of $N .^{6}$ Then we can elaborate (16), the logical form of "Booth shot Lincoln", as (16*):

(16) $\exists e[\operatorname{Shooting}(e) \& \operatorname{Agent}(\boldsymbol{e}$, Booth $) \& \operatorname{Patient}(e$, Lincoln $)]$

(16*) $\exists e\{\operatorname{Shooting}(e) \& \exists a[\operatorname{grounds}(a, e) \& \operatorname{action}(a$, Booth $)] \&$ Patient $(e$, Lincoln $)\}$.

The idea will be that actions, unlike grounded complex events, satisfy the internalist conception. For the moment, the important point is that "Booth's shooting of Lincoln" is ambiguous, if this nominalization of (16) is associated with quantification over two event positions. The event description could be used in referring to: the complex event $e$ (which is With-a-pistol, has Lincoln as its Patient, etc.); or the action $a$ that grounds $e$ (where $a$ has whatever further features it has). Thus, in speaking of the shooting, one could be referring to either of two events, which can be represented with the following descriptions:

$\exists ! e\{\operatorname{Shooting}(e) \& \exists a[\operatorname{grounds}(a, e) \& \operatorname{action}(a$, Booth $)] \&$ Pa$\operatorname{tient}(e$, Lincoln $)]\}$; or

$\exists ! a\{\operatorname{action}(a$, Booth $) \& \exists e[\operatorname{Shooting}(e) \&$ grounds $(a, e) \& \mathrm{~Pa}-$ $\operatorname{tient}(e$, Lincoln $)]\}$.

There is room for disagreement about whether $\left(16^{*}\right)$ provides a more detailed representation of the sentence's true logical form, or whether it merely combines the representation of logical form in (16) with an important truth about what it is to be the Agent of an event. Correspondingly, there is room for disagreement about whether the ambiguity is genuinely semantic, or a pragmatic ambiguity that arises because of speakers' (tacit) recognition of the relation between Agents and actions. I

${ }^{6}$ Hedging seems unavoidable. Hart and Honoré (1959) note that a second party can "break the chain" of responsibility between a first person's action and its effects. Nora did not burn the forest, if: her campfire (which would have spread) is nearly extinguished by a passerby, who then comes to think that burning the forest would be fun after all-and so rekindles the fire. Perhaps no event has as parts both Nora's action and the forest's burning. But I may need the notion of being responsible for an event, where a person is responsible for only some events grounded by her actions: $\operatorname{Agent}(e, N) \leftrightarrow \exists a[\operatorname{grounds}(a, e) \&$ action $(a, N) \& \operatorname{responsible}(N, e)]$. For ease of presentation, however, I ignore this complication. A more important complication (to which I return) concerns sentences like "The rock broke the window", where the subject performs no action. 
will not try to resolve these issues here; though I return to them in $\S 5$ below.

Initially, one might have been attracted to a simpler view of how Agents are related to actions: $\operatorname{Agent}(e, N)$ iff $\operatorname{action}(e, N)$. Indeed, this thesis seems to be what generates our puzzle. Given that Booth is the Agent of a certain shooting, it follows from the simple view that the shooting is one of Booth's actions. From here, the road to paradox is short: semantic and spatiotemporal considerations strongly suggest that the shooting is a complex event having parts that are changes external to Booth; so if the shooting is one of Booth's actions, then actions include events with parts that are changes external to actors; but this is just what the internalist conception of action rules out. I think the trouble lies in the inference from the claim that Booth is the Agent of a shooting to the claim that the shooting is an action. This inference is not licensed by: $\operatorname{Agent}(e, N) \leftrightarrow$ $\exists a$ [grounds $(a, e) \&$ action $(a, N)]$.

Let me be explicit about this crucial point. Since "Agent" is a quasitechnical notion of semantic theory, its relation to the notion of action (a quasi-technical notion from the philosophy of thought) need not be trivial. If the relation is the one I suggest, we can endorse the internalist conception, according to which a person's actions do not include events with parts external to her. For if we do not presuppose the simple view, we need not say that a person's actions include all the events of which she is the Agent.

This lets us speak of the action that grounds a complex event. As Davidson (1971, p. 49) says, at least some actions must be "primitive", in that they "cannot be analysed in terms of their causal relations" to other actions. If $N$ is the Agent of $e, e$ is grounded by an action of $N$ not grounded by any other action of $N$. Otherwise, infinitely many events would be $N$ 's actions; and a person makes finitely many contributions to history, even if those contributions have infinitely many distinct effects. It does not strictly follow that the only action that grounds a complex event is its primitive grounder. But there is no reason to deny this. If $a$ is the primitive grounder of $e$, then $a$ grounds every grounder of $e$. Any event that $a$ grounds (apart from itself) has effects of $a$ as parts. One will not track the causal contributions of persons with the notion of "action", if actions include events that have effects of other actions as parts.?

\footnotetext{
${ }^{7}$ So I think it best to say that all actions are primitive; see $\$ 1.2$ above. It may be that Nora's action (at $1 \mathrm{pm}$ ) of setting an alarm (to go off at $2 \mathrm{pm}$ ) causes her later action of leaving the house (for an appointment at $3 \mathrm{pm}$ ). But Nora's own mental events and mental states intervene; see note 6 above. So her later action is not a mere effect of her earlier action. Nora responds to the alarm as she does because of her beliefs and desires, while the alarm goes off without further contributions by Nora. With such cases set aside, there is no reason to say that effects of actions are themselves actions.
} 


\section{3}

To summarize: if Booth shot Lincoln, $\exists e[\operatorname{Shooting}(e) \& \operatorname{Agent}(e$, Booth) $\&$ Patient $(e$, Lincoln $)]$; and if Agency is related to action as proposed, $\exists e\{\operatorname{Shooting}(e) \& \exists a[\operatorname{action}(a, \operatorname{Booth}) \&$ grounds $(a, e)] \&$ Patient $(e$, Lincoln)\}. Since "Booth's shooting of Lincoln" is associated with quantification over two event positions, it can be used in referring to the complex event $e$ (which is not an action), or to the action $a$ that grounds $e$. So let us introduce subscripts as follows: Booth' $\mathrm{s}_{\mathrm{E}}$ shooting of Lincoln was not his $\mathrm{E}_{\mathrm{E}}$ pulling of the trigger; only the $\mathrm{E}_{\mathrm{E}}$ shooting was With-a-pistol; only the $\mathrm{E}_{\mathrm{E}}$ pulling was With-his-finger; and neither complex event was an action; but Booth's $\mathrm{A}_{\mathrm{A}}$ shooting of Lincoln was his ${ }_{\mathrm{A}}$ pulling of the trigger; though the $\mathrm{E}_{\mathrm{E}}$ shooting was not the $\mathrm{A}_{\mathrm{A}}$ shooting, and the $\mathrm{E}_{\mathrm{E}}$ pulling was not the $\mathrm{A}_{\mathrm{A}}$ pulling. Identificationists are right about actions, while anti-identificationists are right about the complex events (grounded by actions) that satisfy sortal terms like "shooting" and get modified by phrases like "with a pistol".

If "shooting" is true of complex events, Booth's ${ }_{\mathrm{A}}$ shooting of Lincoln was not an event that satisfied "shooting", and one can use nominalized action sentences to refer to events grounded by (though not identical with) actions. But these are small costs to pay for preserving the event analysis and the internalist conception of action. Anti-identificationist intuitions also get their due. For

(11) Booth killed Lincoln on April 13, but Lincoln did not die until April 14

is false, if every part of an On-April-13 event must occur on April 13. Given this assumption, $\neg \exists e\{\operatorname{Killing}(e) \& \exists a[\operatorname{action}(a$, Booth $) \&$ grounds $(a, e)] \&$ Patient $(e$, Lincoln $) \&$ On-April-13(e) $\}$, since the $\mathrm{E}_{\mathrm{E}}$ killing had parts that had not yet occurred on April 13. Similarly, the $e_{\mathrm{E}}$ killing had parts that did not occur in Ford's theater. None the less, the $\mathrm{A}_{\mathrm{A}}$ killing occurred on April 13 in Ford's Theater.

On any view, we typically refer to actions by using sortal terms like "pulling" and "shooting". So if such terms are true of complex events, the anti-identificationist's favored events should be welcomed. But these events are grounded in actions, about which the identificationist is right. In short, identificationist and anti-identificationist intuitions are not in tension. They come as a package.

${ }^{8}$ Thus, Booth's $\mathrm{s}_{\mathrm{A}}$ shooting of Lincoln has the same causes and effects as Booth' $\mathrm{s}_{\mathrm{A}}$ pulling of the trigger. All that differs here are the action descriptions, although the action is described as the ground of different complex events, not as the cause of distinct effects. 


\section{Moving bodies}

Distinguishing complex events from their grounders saves the internalist conception of action. But it invites the question: what sort of event is an action? Again, Booth's action of shooting Lincoln was not $a_{E}$ shooting. Yet if Booth's action was not $a_{E}$ shooting (or $a_{E}$ pulling), what was it? The following picture, where the squares represent proper parts of the overlapping complex events, may help render the question vivid:

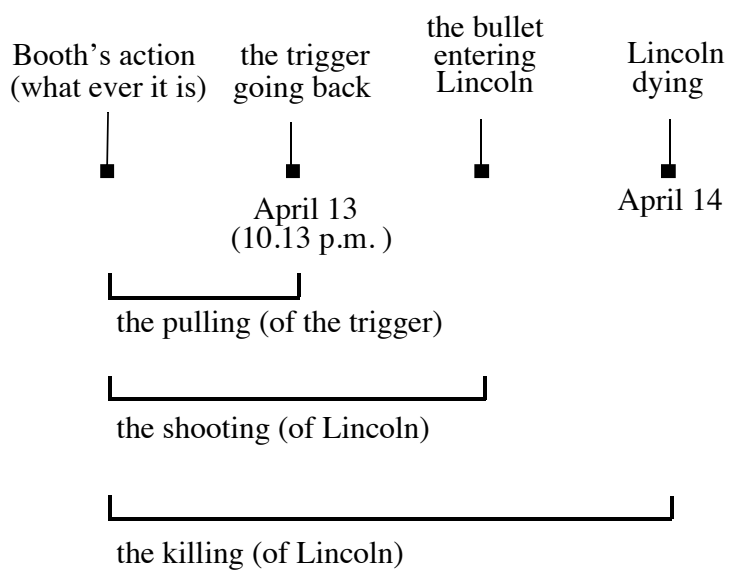

A common suggestion is that actions are bodily motions - or at least that many bodily motions are actions. But I know of no good argument for this thesis, except that it can be hard to think of a coherent alternative; and as we will see, there is reason for seeking an alternative. My strategy, though, will be to sneak up on the ontological question. First, I want to consider entailments like:

(12) Nora melted $\mathrm{T}_{\mathrm{T}}$ the chocolate, so the chocolate melted $_{\mathrm{I}}$.

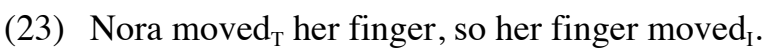

The best account of such entailments suggests that actions cause bodily motions. (In what follows, I draw heavily on Hornsby (1980); though she does not frame the issue in terms of grounded events.)

\section{1}

The inferences in (12) and (23) are examples of a more general pattern. For a wide class of tensed verbs " $V$ ", the following inference is valid: Nora $\mathrm{V}_{\mathrm{T}} \ldots$, so __ $\mathrm{V}_{\mathrm{I}}$; where subscripts indicate transitive/intransitive forms of the verb, and the blank is filled by some description or name. In

(24) Nora raised $_{\mathrm{T}}$ her arm/glass/flag, so her arm/glass/flag rose $_{\mathrm{I}}$ 
we still have transitive and intransitive forms of the same verb, I assume, despite the phonetic variation.

Talk of moving fingers and raising arms is likely to trigger metaphysical views, which will muddy our semantic intuitions. So for now, let us focus on:

(25) Nora melted $_{\mathrm{T}}$ the chocolate.

(26) The chocolate melted $\mathrm{I}_{\mathrm{I}}$

On a straightforward application of the event analysis, the logical form of (25) is:

(25a) $\exists e\left[\operatorname{Melting}_{\mathrm{T}}(e) \& \operatorname{Agent}(e\right.$, Nora $) \& \operatorname{Patient}(e$, the chocolate $\left.)\right]$.

Elaborating “Agent $(e$, Nora)", as suggested in $\$ 2.2$, yields:

$\left(25^{*}\right) \exists e\left\{\operatorname{Melting}_{\mathrm{T}}(e) \& \exists a[\operatorname{grounds}(a, e) \operatorname{action}(a\right.$, Nora $)] \&$

Patient $(e$, the chocolate $)\}$.

One can use "Nora's melting ${ }_{\mathrm{T}}$ of the chocolate" in referring to Nora' $\mathrm{S}_{\mathrm{E}}$ melting $_{\mathrm{T}}$ of the chocolate or Nora's $\mathrm{s}_{\mathrm{A}}$ melting $_{\mathrm{T}}$ of the chocolate (a com-

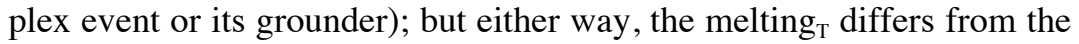

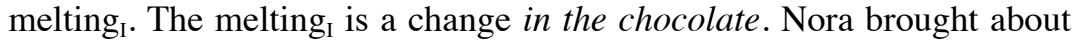
this change, but only with the help of nature. The melting ${ }_{I}$ occurred after Nora did her bit-say, putting the chocolate in a hot pot. So the melting is not Nora's action; and neither is the melting ${ }_{\mathrm{I}}$ a complex event grounded by her action. Rather, there are three events here: the melting the $_{\mathrm{A}}$ melting $_{\mathrm{T}}$, and the $\mathrm{E}_{\mathrm{E}}$ melting $_{\mathrm{T}}$. The first two are parts of the third; the second grounds the third; and crucially, the $_{\mathrm{A}}$ melting $_{\mathrm{T}}$ causes the melting . $_{\text {. }}$

While the thematic structure of (26) is not obvious, the chocolate seems to be saliently affected, as opposed to a salient initiator. So let us (tentatively) take the logical form of (26) to be:

(26a) $\exists f\left[\operatorname{Melting}_{\mathrm{I}}(f) \& \operatorname{Patient}(f\right.$, the chocolate $\left.)\right]$.

Say that event $F$ culminates event $E$, if: $F$ and $E$ both occur; $F$ is a (perhaps improper) part of $E$; and $F$ is an effect of every event that is a proper part of $E$ but is not a part of $F$. It follows that every event culminates itself. Let us assume that a melting $\mathrm{T}_{\mathrm{T}}$ (of $y$ ) culminates in a melting $\mathrm{I}_{\mathrm{I}}$ (of $y$ ). That is

$$
\operatorname{Melting}_{\mathrm{T}}(e) \text { iff } \exists f\left[\operatorname{Melting}_{\mathrm{I}}(f) \& \operatorname{Culminates}(f, e)\right]
$$

\footnotetext{
${ }^{9}$ Indeed, this difference alerts us to a distinction that can go unnoticed elsewhere (even though many theorists have noticed it). Other verbs that seem to fit this pattern include: "shattered", "broke", "boiled", "froze", "sank", "increased", "emptied", "opened", "closed", "hanged", "felled"; etc. See Parsons (1990) for discussion and more examples. The oddness of saying "the door closed $_{\mathrm{I}}$ ", in a context where someone $\operatorname{closed}_{\mathrm{T}}$ the door, is presumably a pragmatic effect.
} 
Patient $(e, y)$ iff $\exists f[\operatorname{Culminates}(f, e) \& \operatorname{Patient}(f, y)]$.

Then the melting $\mathrm{s}_{\mathrm{T}}$ are: the meltings $\mathrm{s}_{\mathrm{I}}$ and events grounded by actions that culminate in meltings $\mathrm{I}_{\mathrm{I}} \cdot{ }^{10}$

It will be easier to deploy this suggestion if (25a) is rewritten as

(25b) $\exists e\left\{\left[\operatorname{Melting}_{\mathrm{T}}(e) \&\right.\right.$ Patient $(e$, the chocolate $\left.)\right] \& \operatorname{Agent}(e$, Nora $\left.)\right\}$.

This reflects the independently plausible idea that a direct object is the internal argument of a transitive verb. That is, " $\mathrm{V}_{\mathrm{T}}$-object" is a semantic unit, while "subject- $\mathrm{V}_{\mathrm{T}}$ " is not. Now we can elaborate (25b) as:

(25c) $\exists e\left\{\exists f\left[\operatorname{Melting}_{\mathrm{I}}(f) \& \operatorname{Culminates}(f, e) \& \operatorname{Patient}(f\right.\right.$, the chocolate $\left.)\right]$ $\& \operatorname{Agent}(e$, Nora $)\}$.

The suggestion is that $(25 \mathrm{c})$ is the logical form of (25); the surface (transitive) form conceals structure. Given (25c), (26a) follows trivially; and this explains why (26) follows from (25). But Nora is still represented as

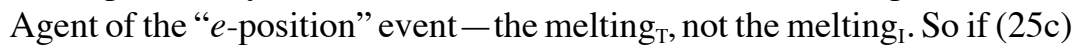
is true, then $\exists e\left\{\exists f\left[\operatorname{Melting}_{\mathrm{I}}(f) \& \operatorname{Culminates}(f, e) \& \operatorname{Patient}(f\right.\right.$, the chocolate) $] \& \exists a$ [grounds $(a, e) \&$ action( $(a$, Nora $)]\}$, given my proposal about how Agents are related to actions. That is, an action of Nora's grounds an event that culminates in a melting $\mathrm{I}_{\mathrm{I}}$ of the chocolate. This seems to give the right truth conditions for (25).

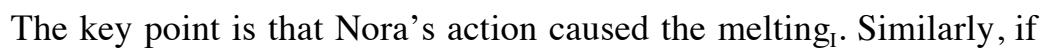
Nora raised ${ }_{\mathrm{T}}$ the flag, the flag rose ${ }_{\mathrm{I}}$; and Nora's action is distinct from

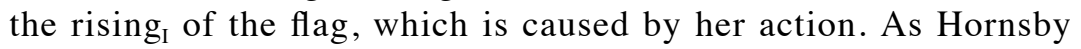
(1980) notes, actions are reported by using the transitive form of verbs in this class. One says what Nora did, by saying: she melted $_{\mathrm{T}}$ the chocolate; she $\operatorname{raised}_{\mathrm{T}}$ the flag; she moved $\mathrm{T}_{\mathrm{T}}$ her hand; etc. One does not say what Nora did by saying: the chocolate $\operatorname{melted}_{I}$; the flag $\operatorname{rose}_{I}$; her hand moved $_{\mathrm{I}}$; etc. At least where the relevant Patient is some chocolate or a flag, it seems that Nora's action caused the event specified with the intransitive form.

\footnotetext{
${ }^{10}$ See notes 3 and 5. Parsons (1990) also speaks of events culminating, though in a slightly different sense. (For simplicity, I am ignoring a host of difficult questions concerning the logical form ... progressive paradox; see Parsons for discussion.) It might be suggested that the logical form of " $Y$ melted" is " $\Delta$ melt$\mathrm{ed}_{\mathrm{T}} Y$ "; where " $\Delta$ " is an unvoiced subject. On this view, " $Y$ melted" entails that something melted $Y$; but if there is an entailment here, I do not think it is semantic. (Contrary intuitions may stem from our faith that every event has a cause.) Similarly, I doubt that the verb in " $Y$ melted" assigns $t w o$ thematic roles. Still, " $Y$ melted $_{\mathrm{I}}$ " may result from movement-i.e. the argument of "melt" may be its logical object - thus making it more plausible that $Y$ is a Patient. (See Burzio 1986 and Baker 1988, pp. 46-7.) But defenders of this attractive view must say why "There melted $_{I}$ some chocolate" and "There sank I $_{\mathrm{I}}$ three ships" are less acceptable than similar expletive constructions like "There seems to be a mistake" and "There arrived three men". (Cf. Belletti 1988 and Haegeman 1994, pp. 3317.)
} 


\section{2}

Let us now consider:

(27) Nora moved $_{\mathrm{T}}$ her finger.

(28) Her finger moved $_{\mathrm{I}}$.

On a straightforward application of the event analysis, the logical forms are:

(27a) $\exists e\left\{\left[\operatorname{Moving}_{\mathrm{T}}(e) \& \operatorname{Patient}(e\right.\right.$, her finger $\left.)\right] \& \operatorname{Agent}(e$, Nora $\left.)\right\}$.

(28a) $\exists f\left[\right.$ Moving $_{\mathrm{I}}(f) \& \operatorname{Patient}(f$, her finger $\left.)\right]$.

If we treat "move " like "melt ${ }_{\mathrm{T}}$ ", we will elaborate (27a) as follows

(27b) $\exists e\left\{\exists f\left[\operatorname{Moving}_{\mathrm{I}}(f) \& \operatorname{Culminates}(f, e) \& \operatorname{Patient}(f\right.\right.$, the chocolate $\left.)\right]$ $\& \operatorname{Agent}(e$, Nora $)\}$.

Given (27b), (28a) follows trivially; and this explains why (28) follows from (27). In (27b), Nora is represented as the Agent of the " $e$-position" event - the moving $_{\mathrm{T}}$, not the moving ${ }_{\mathrm{I}}$. So given (27)

$\exists e\left\{\exists f\left[\operatorname{Moving}_{\mathrm{I}}(f) \& \operatorname{Culminates}(f, e) \& \operatorname{Patient}(f\right.\right.$, the chocolate $\left.)\right]$ $\& \exists a[\operatorname{grounds}(a, e) \& \operatorname{action}(a$, Nora $)]\}$.

That is, some action of Nora's grounds an event that culminates in a moving $_{\mathrm{I}}$ of her finger. (We typically speak of motions, not movings . But I assume the movings s $_{\mathrm{I}}$ are the motions; see note 1.)

This strongly suggests that Nora's action caused the moving of her finger; her action caused the finger motion, just as Nora's action causes the melting $_{\mathrm{I}}$ of the chocolate. A similar treatment of " raised $_{\mathrm{T}}$ " suggests that, when Nora raises $\mathrm{T}_{\mathrm{T}}$ her hand, her action causes the rising ${ }_{\mathrm{I}}$ of her hand. But, alas, showing that actions cause bodily motions is not quite this easy. While I want to treat "move" fully on a par with "melt", one might adopt another view, trading on the fact that every event grounds (and culminates) itself: if Nora moved $_{\mathrm{T}}$ her finger, her action grounds an event that

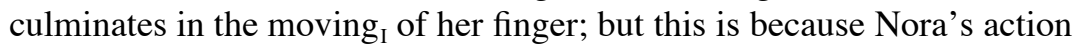
is the moving I $_{\mathrm{I}}$ of her finger, not because her action causes the moving $\mathrm{I}_{\mathrm{I}}$ of her finger. Before arguing against this view, I want to dwell a bit on the loophole that lets one say that (some) bodily motions are actions. In this context, it will be useful to contrast my proposal with a more familiar variant that rules out the possibility of identifying Nora's action with her finger motion.

One might have said that the logical form of (25), repeated here along with $(26)$, is (25pca):

(25) Nora melted $_{\mathrm{T}}$ the chocolate.

(26) The chocolate melted

(25pca) $\exists e\left\{\operatorname{Agent}(e\right.$, Nora $) \& \exists f\left[\operatorname{Melting}_{\mathrm{I}}(f) \& \operatorname{Patient}(f\right.$, the chocolate $)$ $\&$ Cause $(e, f)]\}$. 
From (25pca), it follows that: $\exists f\left[\operatorname{Melting}_{\mathrm{I}}(f) \&\right.$ Patient $(f$, the chocolate)]. This is the logical form of (26). So the "pure causative analysis" of (25) explains why (25) entails (26). Parsons (1990) develops this proposal in some detail, noting that many other theorists (even those not working within the event analysis framework) have had essentially the same view. Hornsby (1980) also urges the pure causative analysis. On this account, (25) says that Nora is the Agent of an event that causes a melting ${ }_{\mathrm{I}}$ of the chocolate; whereas on my view, (25) says that Nora is the Agent of an event that culminates in a melting $\mathrm{I}_{\mathrm{I}}$ of the chocolate. This can seem like a distinction without a difference. If (25) is true, Nora's action did cause the melting ${ }_{\mathrm{I}}$; and no one denies that Nora is the Agent of her actions. ${ }^{11}$ But it need not be part of the meaning of (25) that Nora is the Agent of a cause of the melting .

This matters when we turn to (27-28), with (27pca) being the hypothesized logical form of (27):

(27) Nora moved $_{\mathrm{T}}$ her finger.

(28) Her finger moved $\mathrm{I}_{\mathrm{I}}$.

(27pca) $\exists e\left\{\operatorname{Agent}(e\right.$, Nora $) \& \exists f\left[\operatorname{Moving}_{\mathrm{I}}(f) \&\right.$ Patient $(f$, the chocolate $)$ $\&$ Cause $(e, f)]\}$.

From (27pca), it follows that: $\exists f\left[\operatorname{Moving}_{\mathrm{I}}(f) \&\right.$ Patient $(f$, the chocolate)]. So the pure causative analysis nicely explains why (27) entails (28). It also follows from (27pca) that Nora is the Agent of an event that causes the moving $\mathrm{I}_{\mathrm{I}}$ of her finger. But one might dispute this, holding that (27) can be true when Nora's action is the moving ${ }_{I}$ of her finger. In fact, one might cite the internalist conception of action in arguing for an asymmetry between "melt" and "move": the melting of the chocolate is external to Nora (beyond her control, etc.) in a way that the moving I $_{\mathrm{I}}$ her finger is not. And one need not analyze (27) as (27pca) to explain why (27) entails (28).

That is, given the availability of my proposed variant on the pure causative analysis, one cannot argue that actions cause bodily motions simply by offering the pure causative analysis of verbs like "melt", and then noting that "move" belongs to the relevant class of verbs. This is not to deny that semantic arguments can play a role here. On the contrary, other things being equal, we should treat "melt" and "move" on a par semantically; for these verbs seem to be on a par syntactically. So I am suspicious of the claim that Nora's action causes a melting in $_{\mathrm{I}}(25)$, while her action is a moving $_{\mathrm{I}}$ in (27). To my ear, this sounds like a refusal to follow the semantics where it leads, because of prior metaphysical commitments; and I

\footnotetext{
${ }^{11}$ This is common ground between the simple view-Agent $(e, N)$ iff action $(e$, $N)$ - and my proposed alternative: $\operatorname{Agent}(e, N)$ iff $\exists a[\operatorname{action}(a, N) \& \operatorname{grounds}(a$, $e)]$.
} 
think we do better by letting semantics be our guide to metaphysics. But these considerations are not yet decisive.

\section{3}

If one could defend the pure causative analysis, as opposed to my variant, that would close the loophole in the argument for treating actions as causes of bodily motions. But this strategy is unpromising. Let me conclude this section by saying why; $\S 4$ offers a better strategy.

The explanations of relevant entailments are formal; they make no appeal to causation per se. We can without loss restate the causative analysis of (25) as $\left(25-R_{c}\right)$

(25) Nora melted ${ }_{\mathrm{T}}$ the chocolate

$\left(25-\mathrm{R}_{\mathrm{c}}\right) \exists e\left\{\operatorname{Agent}(e\right.$, Nora $) \& \exists f\left[\operatorname{Melting}_{\mathrm{I}}(f) \& \operatorname{Patient}(f\right.$, the chocolate $)$ $\left.\left.\& \mathrm{R}_{\mathrm{c}}(e, f)\right]\right\}$

where $R_{c}$ is some relation that holds between an event of which Nora is the Agent and the melting ${ }_{\mathrm{I}}$ of the chocolate. The relation $\mathrm{R}_{\mathrm{c}}$ will have something to do with causation, hence the subscript; for it must "fit" with the notion of being an Agent, which has something to do with causation. In general, $\mathrm{R}_{\mathrm{c}}$ must be such that: if $x$ melted $_{\mathrm{T}} y$, then $x$ is the Agent of an event that bears $\mathrm{R}_{\mathrm{c}}$ to a melting $\mathrm{I}_{\mathrm{I}}$ of $\mathrm{y}$; and similarly for other verbs in this class. But it does not follow that $R_{c}$ is the relation of causation. It could be the relation causes-or-is (where Nora is the Agent of her actions), or the relation culminates (where Nora is the Agent of those events, many of which are complex, grounded by her actions). On either view, the moving of Nora's hand would bear $R_{c}$ to itself, if the moving ${ }_{I}$ is one of Nora's actions. $^{12}$

Of course, entailments do not exhaust the possible data. But other evidence tells against appealing to causation itself in the semantics. Suppose Nora melted $_{\mathrm{T}}$ the chocolate (outside, on a chilly day) by moving $\mathrm{T}_{\mathrm{T}}$ a lens between the chocolate and the sun. And consider the following instance of our initial puzzle:

(29) Nora melted T $_{\mathrm{T}}$ the chocolate with her lens.

(30) Nora moved $\mathrm{T}_{\mathrm{T}}$ the lens with her hand.

(31) Nora melted $\mathrm{T}_{\mathrm{T}}$ the chocolate with her hand.

(32) Nora moved $_{\mathrm{T}}$ the lens with her lens.

${ }^{12}$ As many authors have noted, one can account for the entailments without saying that the English word "cause" figures in the logical form of sentences like (25). One can use a technical notion "Cause" whose extension differs from that of "cause". So the basic analysis cannot be refuted by describing odd cases in which Nora's action caused the melting ${ }_{\mathrm{I}}$ of the chocolate, though it seems wrong to say that Nora melted ${ }_{\mathrm{T}}$ the chocolate. But if one can replace "cause" with a technical variant, one can replace "cause" with other causal notions, given compensating adjustments to the extension of " $\operatorname{Agent}(e, N)$ ". 
I take it that (29-30) can be true, while (31-32) can not. This is a problem, if the logical form of "Nora $\mathrm{V}_{\mathrm{T}}$ " " is: $\exists e\{\operatorname{Agent}(e$, Nora) \& $\exists f\left[\mathrm{~V}_{\mathrm{I}}\right.$-ing $\left.\left.(f) \& \operatorname{Patient}(f, \ldots) \& \operatorname{Cause}(e, f)\right]\right\}$. For when we consider the need to accommodate adjuncts, no treatment is satisfactory. Since the

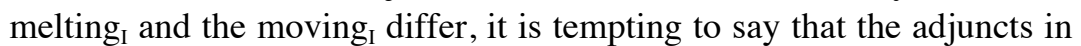
(29-32) modify the caused events, that is the events in the " $f$-position". But as Parsons (1990, pp. 164-5) notes, it seems that the instrumental "with ..." must modify the causing event on this analysis. Intuitively, "with ..." modifies what Nora did, not what happened to the chocolate/ lens. Moreover, "the chocolate melted $_{I}$ with her lens/hand" and "the lens $\operatorname{moved}_{\text {I }}$ with her lens/hand" are barely intelligible; yet the intransitive verbs easily take modifiers, as in "the chocolate melted $\mathrm{I}_{\mathrm{I}}$ slowly on Monday". (Similarly: if Nora closed ${ }_{\mathrm{T}}$ the door with her foot, the door closed $_{\mathrm{I}}$, but not with her foot; and if she broke $\mathrm{T}_{\mathrm{T}}$ the vase with a hammer, the vase broke , but not with a hammer.)

Thus, there seem to be two events here: Patient $(e 1$, the chocolate) \& With-her-lens $(e 1) \& \neg$ With-her-hand $(e 1)$; Patient $(e 2$, the lens) $\& \neg$ Withher-lens $(e 2) \&$ With-her-hand $(e 2)$. This makes it plausible that $e 1$ and $e 2$ are complex events with different end points: $e 1$ is a melting ${ }_{\mathrm{T}}$ of the chocolate, $e 2$ is a moving ${ }_{\mathrm{T}}$ of Nora's lens. But then $e 1$ does not cause the event $f 1$ that is the melting $; e 1$ culminates in $f 1$, which is caused by the action that grounds $e 1$. And $e 2$ does not cause the event $f 2$ that is the moving $; e 2$ culminates in $f_{2}$, which is caused by the action that grounds $e 2$. One can perhaps identify Nora's action of melting ${ }_{\mathrm{T}}$ the chocolate with Nora's action of moving ${ }_{\mathrm{T}}$ her lens. But this is no longer the pure causative analysis, it is my variant.

Let me put the point another way. It seems that (pace Parsons) the instrumental "with ..." does not modify a causing event, but rather a complex event-or if you like, a process that begins with the relevant action and culminates with the event specified by the intransitive verb. It is important, though, to distinguish logical forms from claims that are merely true. On any plausible view, Nora's action causes the melting $_{\mathrm{I}}$ of the chocolate. And I readily grant that Nora is the Agent of her actions, since each of her actions is grounded by itself. So I can hardly deny

(25pca) $\exists e\left\{\operatorname{Agent}(e\right.$, Nora $) \& \exists f\left[\operatorname{Melting}_{\mathrm{I}}(f) \& \operatorname{Patient}(f\right.$, the chocolate $)$ $\&$ Cause $(e, f)]\}$.

But were this the logical form of "Nora melted ${ }_{\mathrm{T}}$ the chocolate", the logical form of (29) would be

(33) $\exists e\left\{\operatorname{Agent}\left(e\right.\right.$, Nora) $\& \exists f\left[\operatorname{Melting}_{\mathrm{I}}(f) \& \operatorname{Patient}(f\right.$, the chocolate $)$ $\&$ Cause $(e, f)] \&$ With-her-lens $(e)\}$. 
I do not think that any cause (or Cause) of the melting ${ }_{\mathrm{I}}$ is With-her-

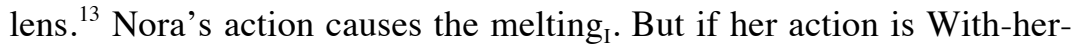
lens, then by parity of reasoning, it should also be With-her-hand. Yet if Nora's action is With-her-hand, then

(34) $\exists e\left\{\operatorname{Agent}\left(e\right.\right.$, Nora) \& $\exists f\left[\operatorname{Melting}_{\mathrm{I}}(f) \& \operatorname{Patient}(f\right.$, the chocolate $)$ $\&$ Cause $(e, f)] \&$ With-her-hand $(e)\}$.

If (33) were the logical form of (29), then (34) would be the logical form of (31). This incorrectly predicts that (31) is true. So I conclude that these are not the correct logical forms.

Moreover, suppose one could somehow treat "with ..." as a modifier of the caused event in (29-32). This would threaten the response to our original puzzle. Consider:

(2) Booth shot Lincoln with a pistol.

(35) Booth pulled the trigger with a pistol.

The explanation for why (2) is true, while (35) is false, is that the shooting and the pulling are distinct complex events. On my view, the logical form of (2) is

(2b) $\exists e[\operatorname{Shooting}(e) \& \operatorname{Agent}(e$, Booth $) \&$ Patient $(e$, Lincoln) \& With-a-pistol $(e)]$.

But here, there seems to be no reference to any caused event for the adjunct to modify. ${ }^{14}$ So there is good reason to modify the pure causative analysis along the lines I have suggested. Hence, one cannot use the pure causative analysis to establish that actions cause bodily motions.

\footnotetext{
${ }^{13}$ The complex melting ${ }_{\mathrm{T}}$ culminates with, but does not cause, the melting If $_{\mathrm{I}}$ one appeals to a complex event that culminates sooner (perhaps the moving $\mathrm{T}_{\mathrm{T}}$ ), it is still not clear that the complex event would cause the melting I $_{\text {. If one defines }}$ "Cause" to ensure that the moving ${ }_{\mathrm{T}}$ Causes the melting ${ }_{\mathrm{I}}$, other examples will reproduce the objection discussed in the text. (See also note 6.)

${ }^{14}$ One might reply that all transitive action verbs are causatives, with (2) analyzed as follows: $\exists e \exists f[\operatorname{Agent}(e, \operatorname{Booth}) \& \operatorname{Be}-\operatorname{shot}(f) \& \operatorname{Patient}(f$, Lincoln $) \&$ Cause $(e, f) \&$ With-a-pistol $(f)]$. Lombard (1986) offers a proposal of this sort. Again, this raises issues that I cannot address here; see note 10. But even if every transitive is a causative, why say that the " $e$-position" event causes the " $f$-position" event? It seems that we could restate the analysis of (2), without loss, as: $\exists e \exists f\left[\operatorname{Agent}(e\right.$, Booth $) \& \operatorname{Be}-\operatorname{shot}(f) \& \operatorname{Patient}(f$, Lincoln $) \& \mathrm{R}_{\mathrm{c}}(e, f) \&$ With-apistol $(f)]$. Moreover, if "with a pistol" modifies the " $f$-position" event, the adjunct phrase does not describe one of Booth's actions (or any process that begins with Booth's action and ends with Lincoln being shot). But one wants to say that "with a pistol" modifies Booth's causing of the " $f$-position" event; and the way to capture this intuition is (not by appealing to caused events, but) by saying that adjuncts like "with a pistol" modify complex events.
} 


\section{Locating actions in the head}

We wanted to know what (sort of event) an action is. Reflection on the semantic similarities between "move" and "melt" suggested that actions, whatever they are, cause bodily motions. Yet this view is not mandated by the facts about entailment; there is room to say that actions are bodily motions. My claim has been that if Nora moved $_{T}$ her finger, then

$\exists e\left\{\exists f\left[\operatorname{Moving}_{\mathrm{I}}(f) \& \operatorname{Culminates}(f, e) \& \operatorname{Patient}(f\right.\right.$, her finger $\left.)\right] \&$ $\exists a$ [grounds $(a, e) \&$ action $(a$, Nora $)]\}$.

This is certainly compatible with the claim that Nora's action caused the moving $_{\text {I }}$ of her finger. But as we have seen, it is also compatible with the claim that Nora's action is the moving I $_{\mathrm{I}}$ of her finger; perhaps $e=f=a$. None the less, it is not hard to find prima facie arguments against this view of actions, once we take seriously the possibility that actions cause bodily motions. So much of this section is devoted to showing that this possibility is a serious one. This in turn suggests that paradigmatic actions are tryings.

\section{1}

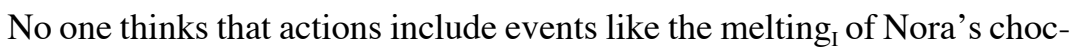
olate. But if Nora's actions include events like the moving ${ }_{\mathrm{I}}$ of her finger, why don't her actions include events like the melting ${ }_{\mathrm{I}}$ of her chocolate? Earlier, I said that one might invoke the internalist conception of action here: the melting ${ }_{\mathrm{I}}$ of Nora's chocolate is external to Nora (and beyond her

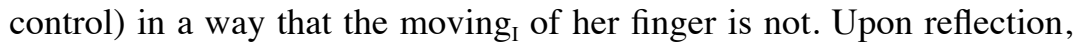
though, this distinction is neither clear nor principled. This casts doubt on the idea that Nora's actions include her finger motions.

Many bodily motions are not actions. Reflexes provide familiar examples. More interesting cases are those in which a person moves $_{\mathrm{T}}$ some part of her body as she might move $_{\mathrm{T}}$ a piece of furniture. Consider

(36) Nora moved $_{\mathrm{T}}$ her finger with a pencil.

(37) Nora raised $\mathrm{T}_{\mathrm{T}}$ her left arm with a pulley.

If (36) is true, Nora's action (whatever it was) caused the moving ${ }_{\mathrm{I}}$ of her finger; and the truth of (37) does not tempt us to identify Nora's action with the rising ${ }_{\mathrm{I}}$ of her left arm. In these cases, the relevant bodily motions seem like the motion of a rock after the thrower has released it. The moving ${ }_{\mathrm{I}} / \mathrm{rising}_{\mathrm{I}}$ is part of what happens in nature, after Nora has done her bit. So a bodily motion is not intrinsically the kind of event that satisfies the internalist conception of action. This should give us 
pause. For if some of Nora's bodily motions are not actions, but are more like the melting I $_{\text {I }}$ her chocolate, those who say that some of Nora's bodily motions are actions owe an account of the relevant difference.

The obvious - and perhaps only - response lies with appeal to causal history. In one sense, I think such appeals are appropriate: some bodily motions are caused by actions; others (like reflexes) are not. But if one holds that some bodily motions are actions, one will try to characterize the relevant subset of bodily motions in terms of their causal relation to (the acquisition of) beliefs and desires. This will exclude bodily motions with no intentional etiology. There are, however, much harder cases. Consider one from Frankfurt (1988): Smith believes that spilling his drink will signal a confederate that it is time to begin a long-planned crime; Smith comes to believe the time has come; but this makes Smith nervous, which causes his hand to shake, and his glass is upset as a result. Intuitively, the shaking I $_{\mathrm{I}}$ of Smith's hand is not an action, but something that happened to Smith. Such cases prompted a debate about what it is for bodily motions to be caused "in the right way"-or alternatively, what makes a causal chain (ending with a bodily motion) "deviant". But as Frankfurt notes in his critical discussion of the debate, appealing to causal history in this way concedes that "actions and mere happenings do not differ essentially in themselves at all" (p. 69); and this is hardly intuitive. Moreover, I do not know of any satisfactory account of causal deviance. No such account is needed, though, if bodily motions are never actions. One can say that the shaking ${ }_{\mathrm{I}}$ of Smith's hand is odd because,

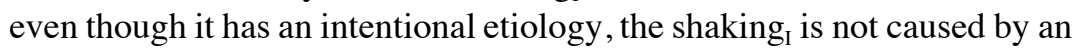
action. (I return to this point below.) While examples like (36-37) may not readily spring to mind, the causal chains here do not seem deviant. On the contrary, they seem on a par with ordinary cases of moving ${ }_{\mathrm{T}}$ chairs and raising ${ }_{\mathrm{T}}$ flags, in which a person's action causes the motion of an object.

One can say that, in (36-37), some other unspecified bodily motion is Nora's action. This concedes that at least some uses of "move" are like

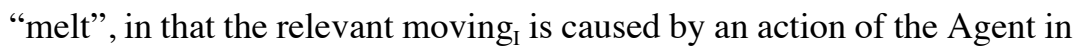
question. A rather striking example of this point is

(38) Nora $_{i}$ moved $_{\mathrm{T}}$ her ${ }_{j}$ finger

where the italicized subscripts indicate that "her" is not referentially dependent on "Nora". It is natural to hear "Nora moved her finger" as meaning that Nora moved her own finger. But this interpretation is not mandatory. If Nora moved $_{\mathrm{T}}$ Sally's finger, Nora's action caused the moving $_{\mathrm{I}}$. So if Nora's action causes the relevant bodily motion in (36-38), the 
simplest hypothesis is that when an Agent moves any finger, her action causes the finger motion in question. ${ }^{15}$

Instead of insisting that history determines which bodily motions are actions, one can identify actions with certain causal antecedents of the relevant bodily motions. There is also independent reason for saying that many actions occur inside persons. Suppose Nora is asked to divide 390 by 13 , and (after a pause) answers " 30 ". Nora did something before answering; she performed a division. This action occurred in her head. We can do many things without moving ${ }_{\mathrm{T}}$ our bodies: figure out the answer to a riddle; prove a theorem; determine whodunnit; read the paper; etc. This does not show that actions are never bodily motions. But it reminds us that actions can and do occur beneath the skin. ${ }^{16}$

\section{2}

With this in mind, consider a puzzle from action theory that Hornsby (1980) focuses on. Suppose Nora wants to contract ${ }_{T}$ the muscles in her forearm-either to show them off, or to make a point about the effects of actions. Nora knows that when she clenches ${ }_{\mathrm{T}}$ her fist, her muscles contract $_{\mathrm{I}}$. So Nora clenches ${ }_{\mathrm{T}}$ her fist. That is, Nora performs a certain action, which can be described as a clenching ${ }_{\mathrm{T}}$ of her fist. It is also true that Nora contracted $_{\mathrm{T}}$ her muscles. So her action can be described as a contracting ${ }_{\mathrm{T}}$ of her muscles. Given identificationist intuitions, we will want to say that Nora's action of clenching ${ }_{\mathrm{T}}$ her fist is Nora's action of contracting ${ }_{\mathrm{T}}$ her muscles. But while Nora's fist clenched ${ }_{I}$, and her muscles contracted $d_{I}$, these are distinct events. Indeed, the clenching ${ }_{\mathrm{I}}$ of Nora's fist was caused

\footnotetext{
${ }^{15}$ Perhaps "Nora moved $_{\mathrm{T}}$ her __" is structurally ambiguous, and the two syntactic forms are correlated with the difference between cases of moving one's body in the usual way, and all other cases. (In conversation, Richard Larson noted

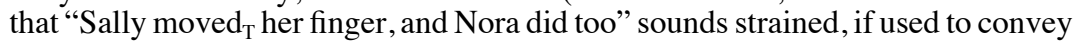

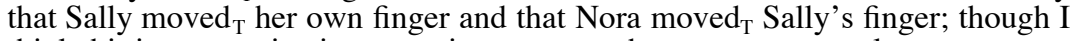
think this interpretation improves in a context where remote controls are common, and someone asks who moved ${ }_{\mathrm{T}}$ Sally's finger.) But given the proposal in the text, I see no reason for saying that "move " is semantically ambiguous (like "bank"), with direct and indirect causation readings (cf. Vendler 1967). This alleged distinction has proven very hard to make out. Moreover, suppose Nick thinks he is looking at Sally, and that Nora moved ${ }_{T}$ Sally's finger by remote control; while in fact, Nick is looking at Nora, who moved her own finger in the usual way. If Nick utters (38), his claim seems true; yet if "moved" has an indirect reading, Nick presumably used it. Perhaps the indirect reading is true, whenever $i=j$ and the direct reading is true. But then the indirect reading does not require indirection; it is like the univocal reading of "move $\mathrm{T}_{\mathrm{T}}$ " discussed in the text. This does not prove that there is no second reading; though given the possibilities for confusion here (see $\S 4.3)$, one wants clear motivation for the second reading.

${ }^{16}$ A reader's eyes move. But an action of reading is not identical with any eye motions. One might say that Nora moves ${ }_{\mathrm{T}}$ internal parts of her body when she reads (or calculates). But not only is this to stretch the ordinary sense of "move it concedes that actions need not be peripheral bodily motions.
} 
by the contracting $\mathrm{I}_{\mathrm{I}}$ contraction of her muscles. (Again, I assume that contractions are contractings ; though we avoid the gerund because we can.) So it cannot be that Nora's action of clenching ${ }_{\mathrm{T}}$ her fist is the clenching ${ }_{\mathrm{I}}$ and that Nora's action of contracting ${ }_{\mathrm{T}}$ her muscles is the contracting ${ }_{\mathrm{I}}$. Moreover, if Nora performed just one action, and that action is the clenching $_{\mathrm{I}}$ of her fist, then: Nora's action of contracting $\mathrm{T}_{\mathrm{T}}$ her muscles is caused by the contracting ${ }_{\mathrm{I}}$ of Nora's muscles.

Even if one is willing to live with this result, the fact remains that "contract" is like "melt" and "move". If Nora contracted ${ }_{\mathrm{T}}$ her muscles, her muscles contracted $_{\mathrm{I}}$. So on the version of the event analysis developed here, the logical form of the transitive construction is: $\exists e\left\{\left[\right.\right.$ Contracting ${ }_{\mathrm{T}}$ (e) \& Patient $(e$, her muscles)] \& $\operatorname{Agent}(e$, Nora) $\}$; or more fully, $\exists e\left\{\exists f\left[\right.\right.$ Contracting $_{\mathrm{I}}(f) \& \operatorname{Culminates}(f, e) \& \operatorname{Patient}(f$, her muscles $\left.)\right] \&$ $\operatorname{Agent}(e$, Nora $)\}$. This treatment is not available, however, if Nora's action is the clenching ${ }_{\mathrm{I}}$ of her fist. For in that case, the " $e$-position" event (the $\mathrm{E}_{\mathrm{E}}$ contracting $_{\mathrm{T}}$ of her muscles) cannot be an event whose grounder is Nora's

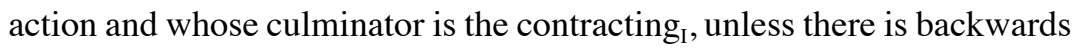
causation. On the other hand, one can avoid any hint of backward causation, by saying that Nora's action (i.e. the clenching $_{\mathrm{T}}$ of her fist, which is also the ${ }_{\mathrm{A}}$ contracting $_{\mathrm{T}}$ of her muscles) causes the contraction of Nora's muscles, which in turn causes the clenching ${ }_{\mathrm{I}}$ of Nora's fist. A picture may make the suggestion vivid:

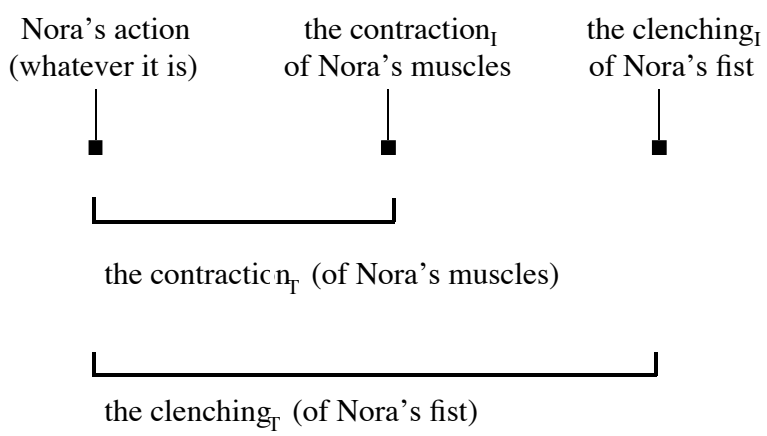

Like Hornsby, I think it is (all things considered) plausible that paradigmatic actions do cause muscle contractions; at a minimum, those who deny this owe another coherent description of what happens when Nora contracts $_{\mathrm{T}}$ her muscles. For now, though, the main point is just that we have reason for saying that some actions can and do cause bodily motions. Given the proposed semantics, at least some actions of clenching ${ }_{\mathrm{T}}$ one's fist are not clenching $\mathrm{S}$ s of one's fist. 
One might try to assimilate such cases to those in which Nora raises her left arm with her right arm. That is, one might grant that the clenching of Nora's fist is the effect of her action, while holding that the causing action is itself a bodily motion. Nora's action is the ${ }_{\mathrm{A}}$ contracting $_{\mathrm{T}}$ of her muscles; so perhaps it will be said that, in this case, Nora's action is her muscle contraction. In one sense, muscle contractions are perfectly fine bodily motions. But once one grants that some actions are not peripheral bodily motions, one owes a reason for insisting that other actions are peripheral. For suppose Nora clenched ${ }_{T}$ her fist, not to show off her muscles, but to grasp some object (or just because she wanted to). If actions are ever bodily motions, Nora's action here is presumably the clenching of her fist. The clenching I $_{\mathrm{I}}$, however, still caused by a contraction of Nora's muscles. And if Nora's actions include some of her muscle contractions, one owes a reason for not identifying Nora's action $\left(\right.$ her $_{\mathrm{A}}$ clenching $_{\mathrm{T}}$ ) with the relevant contraction of her muscles whenever Nora clenches ${ }_{\mathrm{T}}$ her fist.

To appreciate the force of this challenge, consider a third case in which Nora tries to clench $_{\mathrm{T}}$ her fist while her hand is held open. Nora's muscles contract $_{\mathrm{I}}$. Indeed, Nora seems to do her bit, just as when she clenches $_{\mathrm{T}}$ her fist. If her fist fails to clench ${ }_{I}$, Nora still made her causal contribution, much as if she tried to fire a jammed pistol. That is, if Nora's action is a clenching $_{\mathrm{I}}$ when she clenches ${ }_{\mathrm{T}}$ her fist, then her action is a different kind of event when her fist fails to clench; ; but intuitively, the consequent of this conditional is false, since Nora's causal contribution seems the same in both cases. So again, we have reason to say that Nora's action causes the clenching $_{\mathrm{I}}$ (of her fist) when she clenches her fist. $^{17}$

In the last paragraph, I assumed that Nora performs an action when she tries to clench $_{T}$ her fist, even if her fist does not clench $_{\mathrm{I}}$. In general, I assume that a person performs an action when she tries to $\Phi$, even if she does not successfully $\Phi$. Trying to $\Phi$ is doing something, even if it is not $\Phi$-ing. There is, however, something special about sentences like

(39) Nora tried to lift the rock.

The verb "try" takes a propositional complement, and the relevant proposition is not a Patient. For lack of a better term, let us say that "to lift the

\footnotetext{
${ }^{17}$ Perhaps Nora's contribution to the causal order includes the clenching $g_{\mathrm{I}}$ of her fist, when the clenching $\mathrm{I}_{\mathrm{I}}$ is a nondeviant effect of her desires. But this relies on the notion of deviance; and it requires either a bias in favor of the peripheral, or the claim that some (basic) actions are complex events. If one allows talk of non-basic

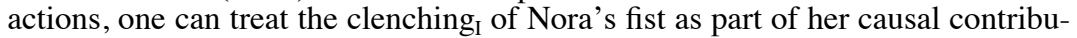
tion, like the motion of a rock after it leaves her hand. But then the question will be whether peripheral bodily motions ever count as basic actions, or whether basic actions are more robustly internal (with bodily motions being like the post-action motions of thrown rocks).
} 
rock" specifies the Content of the trying. On a straightforward application of the event analysis, the logical form of (39) is

(39a) $\exists e[\operatorname{Trying}(e) \& \operatorname{Agent}(e$, Nora) \& Content $(e$, to lift the rock)].

Given my proposal about the relation of Agents to actions, (39a) is true, if and only if $\exists e\{\operatorname{Trying}(e) \& \exists a$ [grounds $(a, e) \& \operatorname{action}(a$, Nora $)] \&$ Content $(e$, to lift the rock)\}. But "try" is not in the relevant class of verbs with "melt", "move", "raise", "clench", "contract". Intuitively, (39) does not say that Nora's action stands in some causal relation to an event specified by some intransitive verb. Rather, (39) reports a feature of the trying itself; it says that an event with a certain content property occurred. So if (39) is true, we are free to say that Nora's trying $i s$ her action. That is, $\exists e\{\operatorname{Trying}(e) \& \exists a[\operatorname{grounds}(a, e) \& \operatorname{action}(a$, Nora $) \& a=e] \&$ Content $(e$, to lift the rock)\}. In this sense, certain action descriptions can "ground out" in the actions themselves. ${ }^{18}$

This fits well with the internalist/identificationist conception of actions. What a person tries to do is within her control, if anything is. Usually, nature must cooperate, if attempts are to be successful. But a person normally has it in her power to try. If (39a) is the right analysis of (39), then a person's actions at least include her tryings; and this suggests that paradigmatic actions are tryings.

I take as given that (39) can be true in a situation where Nora succeeds in lifting the rock. ${ }^{19}$ In such a situation, a (complex) lifting is grounded by one of her actions. That is, $\exists e\{\operatorname{Lifting}(e) \& \exists a[$ grounds $(a, e) \&$ action $(a$, Nora)] \& Patient $(e$, the rock) $\}$. By hypothesis, one of Nora's actions is her trying. And it would be gratuitous to say that some other action of Nora's grounds the complex event that is her lifting of the rock. Nora did not do two separate things - try to lift the rock, and lift the rock. Rather, she per-

${ }^{18}$ I assume that the embedded clause in (39) has an unvoiced subject, which is linked to the matrix subject: Nora ${ }_{i}$ tried $\left[e_{i}\right.$ to lift the rock]. And Nora can initiate her trying without performing an action distinct from it. This does not ascribe strange powers to Nora; Nora can be the initiator of her trying, in that her reasons cause the trying. (I return to this point in \$5.) One might require that an action ground some event other than itself. For it is hard to see how mere tryings would be points at which persons contribute to the causal order. But maybe a recently paralyzed person can try to move ${ }_{\mathrm{T}}$ his arm, even if he cannot produce any effect (in his arm or muscles); cf. McGinn (1982). In any case, I do not insist that all tryings are actions. One can say that only tryings with a causalfuture are actions, or that this is a constraint on genuine tryings.

${ }^{19}$ As O'Shaughnessy $(1973,1980)$ and Hornsby $(1980)$ note, it will be pragmatically inappropriate to say merely that someone tried to $\Phi$ when she succeeded in $\Phi$-ing. Moreover, " $\Phi$-ing" may be conceptually prior to "trying to $\Phi "$, much as "seeing an X" is conceptually prior to "seeming to see an X". (Following Sellars (1956), we can characterize this last notion in terms of being in a condition internally like the condition of seeing an X. So when one sees an X, the event of seeming to see an X can be the event of seeing an X. Similarly, when things go as planned, we can identify tryings with doings.) 
formed one action that can be described (without reference to its effects) as a trying, or as (the ground of) a lifting. So $\exists e\{\operatorname{Lifting}(e) \& \exists a$ [Try$\operatorname{ing}(a) \& \operatorname{grounds}(a, e) \operatorname{action}(a$, Nora $)] \& \operatorname{Patient}(e$, the rock) $\}$, where the relevant action is Nora's trying to lift the rock. Similarly, if Nora successfully tried to move $_{\mathrm{T}}$ her finger, I think Nora's action of moving ${ }_{\mathrm{T}}$ her finger $i s$ the event of her trying. In general, if $N$ tried to $\Phi$ and succeeded, I would identify $N$ 's action of $\Phi$-ing with $N$ 's trying to $\Phi$. (See O'Shaughnessy 1973, 1980.)

If Nora tries to contract $\mathrm{T}_{\mathrm{T}}$ her muscles and succeeds, her action is her trying; and again, I think Nora's action causes the contracting ${ }_{I}$ of her mus-

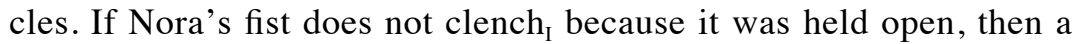
fortiori, her action/trying does not cause a clenching. But Nora's causal contribution is the same, whether or not her fist clenches, ${ }_{1}$, when Nora tries to clench $_{\mathrm{T}}$ her fist. If actions are tryings, actions like mental calculations (standing still, reading, etc.) pose no special difficulties: when Nora tries to do a division and succeeds, her action can be her trying; though in this case, success does not involve a peripheral bodily motion. Returning to Smith, who upset his drink through nervousness, when he realized it was time to give the signal: Smith's beliefs and desires fail to rationalize his behavior, I suggest, because Smith's thoughts did not cause his bodily motion by causing an action/trying (or at least not any trying with the right content-viz. a trying to spill the drink).

On this view, to say that Nora $\operatorname{moved}_{\mathrm{T}}$ part of her body is already to describe an action by reference to its effects (as when we say that Booth shot Lincoln). In fact, Hornsby just pushes a familiar point about actiondescription a bit farther than usual. Again, a picture may help:

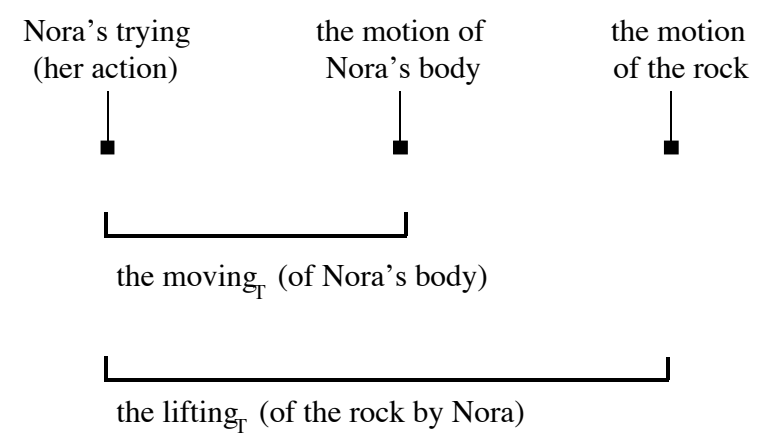

One might identify actions with tryings, yet still insist that when a person moves $_{\mathrm{T}}$ her finger, her action is the motion of her finger. For one might identify successful tryings (to move $\mathrm{T}_{\mathrm{T}}$ one's body) with bodily motions, while perhaps allowing that unsuccessful tryings are inner events (or mus- 
cle contractions). I cannot prove that the class of tryings is not disjoint in this way. ${ }^{20}$ But if the simpler view is available, one begins to suspect that behavioristic/verificationistic scruples are behind the insistence that many actions be bodily motions (whatever the consequences for semantics and our conception of tryings). Of course, the simple view may lead to trouble. So let me turn to some concerns about identifying actions with tryings, where these are understood as mental events that typically have bodily effects.

\section{3}

Clearly, one can do something without trying to do it. If Nora flips the light switch, she may alert the burglar unintentionally. In such a case, Nora's action of alerting the burglar is not a trying to alert the burglar. But Nora's action can still be a trying. In particular, it can be a trying to flip the switch. So I am not saying that anyone who $\Phi$ 'd tried to $\Phi$. If one tries to $\Psi$, one's trying may have an effect in virtue of which one is correctly described as having $\Phi$ 'd, even if one never tried to $\Phi$. (Correspondingly, while " $x$ grounded $y$ " is an extensional context, " $\Phi$ " is an opaque position in "Her trying to $\Phi$ grounded $y$ ".) Nor do I say that all actions are tryings. Nora may act without trying when she "mindlessly" drums her fingers, or "instinctively" ducks under a low doorway. Nora may also act when she decides (or forms the intention) to change jobs; yet I doubt that she tries to decide (or tries to intend). Moreover, if Nora does not vote yes, she may act without her "negative" action being one of her tryings. Such actions require special treatment, however, on any view. My claim is only that paradigmatic (clearly intentional) actions are tryings; though I return to a suggestion about how to deal with some special cases.

Another potential objection is that we cannot see tryings, although it seems that we can see many actions; and of course, we can see bodily motions. But even when it comes to an action like pulling the trigger, it is not clear that we can see the action. In $\S 1$, I said the event analysis lets us render perceptual reports like (14) as (14a)

\footnotetext{
${ }^{20}$ Prima facie, though, such disjointness is at odds with generalizations like the following: If $N$ intends to $\Phi$ when $C$ obtains, and comes to believe that $C$ obtains, then $N$ will try to $\Phi$ (ceteris paribus). If Nora intended to lift the rock at noon, and did so, then on the view being considered: her action/trying is a bodily motion; so the generalization just mentioned often relates intendings to bodily motions. But this seems wrong. If Nora were not strong enough to lift the rock, this would tell us nothing about her intentional profile; and to say that her trying would have been some other event, had Nora failed to lift the rock, is to grant that bodily motions are not what matters to the intentional generalization. Having mentioned intentions, let me note that I have focussed on actions that do not require planning. (Nora can move $\mathrm{T}_{\mathrm{T}}$ her finger without forming an intention and executing a plan.) A full treatment of the relations among actions, tryings, and bodily motions would need to get beyond this massive simplification.
} 
(14) Nora heard Fido bark.

(14a) $\exists e \exists f[\operatorname{Hear}(e$, Nora, $f) \& \operatorname{Bark}(f$, Fido $)]$.

So let us render (40) as (40a), with the relevant portion of thematic structure represented in (40b):

(40) Todd saw Booth pull the trigger.

(40a) $\exists d \exists e[\operatorname{See}(d$, Todd, $e) \&$ Pull( $e$, Booth, the trigger $)]$.

(40b) $\exists d \exists e[\operatorname{See}(d$, Todd, $e) \& \operatorname{Pulling}(e) \&$ Agent $(e$, Booth $) \&$ Patient( $e$, the trigger)].

On this analysis, the event Todd saw was the pulling, not the action that grounds the pulling. If (40) is true, Todd saw what Booth did; what Booth did was pull the trigger; and we can use "the pulling of the trigger" as a means of referring to Booth's action/trying. But (40) entails only that Todd saw the complex " $e$-position" event. So the truth of (40) does not commit me to saying that Todd saw a trying. There is no special reason for denying that we see complex events like pullings, even if such events are grounded by tryings. For we speak of seeing plants, even though they have parts that are below ground. ${ }^{21}$

Even if one identifies actions with tryings, however, one wants some explanation of why it is so tempting to identify actions with bodily motions. So let me conclude this section by noting that, regardless of what actions are, some action descriptions are more primitive than others. If we confuse features of event descriptions with features of the events described, it will seem that bodily motions are more basic than any other candidates for actions.

Modifying Hornsby's (1980) proposals to fit my terminology, say that a description $\Delta$ of action $a$ is more C-basic than another description $\Delta^{*}$ of $a$, if the event corresponding to $\Delta$ is a proper part of the event corresponding to $\Delta^{*}$. Then "Booth's $\mathrm{A}_{\mathrm{A}}$ pulling of the trigger" is more C-basic than "Booth's shooting of Lincoln". The (complex) pulling is a proper part of the (complex) shooting, which has parts that occur after the trigger has gone back. In order of causation, the culmination of the pulling is more basic than the culmination of the shooting. If we forget about contracting ${ }_{\mathrm{T}}$ our muscles, and moving ${ }_{\mathrm{T}}$ our fingers with pencils, it is easy to think that no action descriptions are more $C$-basic than descriptions involving body

\footnotetext{
${ }^{21}$ O'Shaughnessy (1980) would say that a successful trying to move ${ }_{\mathrm{T}}$ one's finger "encompasses" the finger motion. I think his view can be expressed in my terminology, by saying that such a trying is a complex event that culminates with the motion of one's finger. But ceteris paribus, I think considerations of simplicity favour identifying actions with causes of limb motions. More importantly, O'Shaughnessy provides valuable discussion of our epistemic relation to our bodily motions; and I think one can still capture the relation between actions and the bodily motions to which we bear the relevant epistemic relation by saying that actions ground complex events that culminate in such bodily motions.
} 
parts like fingers. This can make it seem that actions must be bodily motions.

Let us also say that a description $\Delta$ of an action $a$ performed by person $x$ is more B-basic than description $\Delta^{*}$, if $x \Delta^{*}$-d by $\Delta$-ing (and not vice versa). Booth killed Lincoln by pulling the trigger; he didn't pull the trigger by killing Lincoln. So "Booth's $\mathrm{A}_{\mathrm{A}}$ pulling of the trigger" is more Bbasic than "Booth's ${ }_{\mathrm{A}}$ killing of Lincoln". Booth pulled the trigger by squeezing his finger, yet he did not squeeze his finger by contracting ${ }_{\mathrm{T}}$ his finger-muscles. So "Booth' $\mathrm{s}_{\mathrm{A}}$ contracting ${ }_{\mathrm{T}}$ of his finger-muscles" is not more B-basic than "Booth' $\mathrm{A}_{\mathrm{A}}$ squeezing of his trigger-finger", although the first event description is more $\mathrm{C}$-basic. This also makes bodily motions seem special. We typically do not move $\mathrm{T}_{\mathrm{T}}$ our bodies by doing anything else; we just move $\mathrm{T}_{\mathrm{T}}$ our bodies. So an action description that involves reference to a bodily motion will typically be more B-basic than any other description of the same action.

One might hope to use this intuition in showing that actions are, after all, bodily motions. But in my view, the "by"-locution positively invites confusion of the causal order with the order of a person's intentions. So I don't think it is helpful, in saying what actions are, to focus on sentences of the form " $x \Delta^{*}$-d by $\Delta$-ing" (cf. Bennett (1988)). One can kill Louis by decapitating him. Arguably, the decapitating is the killing. Yet one cannot decapitate Louis by killing him. Similarly, Nora can move her hand by raising it, without raising her hand by moving it. If actions are bodily motions, however, the raising and the moving are each identical with some motion $m$. So if one identifies actions with bodily motions, one must grant that the "by"-relation can be asymmetric, even given two descriptions of a single event; hence, one must grant that the truth of " $x \Delta^{*}$-d by $\Delta$-ing" is sensitive to more than the mind-independent relations that hold between the events described. So the falsity of "Booth squeezed ${ }_{\mathrm{T}}$ his finger by contracting $_{\mathrm{T}}$ his muscles" hardly shows that Booth did not contract $\mathrm{T}_{\mathrm{T}}$ his muscles, or that the motion of Booth's finger was not caused by Booth's action. $^{22}$

Like Hornsby, I think many of our intuitions here can be accommodated, if we say that a description $\Delta$ of action $a$ is more T-basic than description $\Delta^{*}$, if in virtue of $a$ 's occurrence (and its effects), $x$ intentionally $\Delta^{*}$ 'd by $\Delta$-ing. In order of teleology, "the A $_{\mathrm{A}}$ decapitating of Louis" is more basic than "the $\mathrm{A}_{\mathrm{A}}$ killing of Louis". Typically, there will be no $\Delta$ such that a person intentionally moves $_{\mathrm{T}}$ her fingers by $\Delta$-ing. In this sense, we

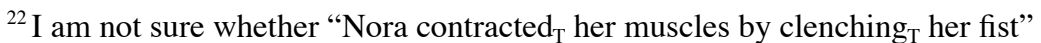
is ever true. (Her action of contracting ${ }_{\mathrm{T}}$ can cause the clenching ${ }_{\mathrm{I}}$, while the "by"sentence is false.) But if this sentence can be true, the "by"-locution would seem to be primarily about intentional (not causal) order.
} 
often bear a special relation to our finger motions. But this does not show that finger motions are among the actions of persons.

Of course, one can define "action" as to include (i) bodily motions caused by tryings, and/or (ii) complex events, grounded by tryings, that culminate in bodily motions. But I see no point to introducing such definitions. Given that actions include tryings, and that tryings cause bodily motions, we need not say that actions include (i) or (ii). Moreover, there is reason not to say this. For it makes the semantics of action sentences unnecessarily complex; in particular, it precludes us from treating verbs like "move", "raise", and "contract" on a par with "melt". Our language strongly suggests that actions typically cause bodily motions; and this (independently motivated) thesis is defensible.

\section{Being an agent without trying}

Since my claims about actions have been based largely on semantic considerations, I must address some loose ends in the proposed semantics.

\section{1}

On a straightforward application of the event analysis, the logical form of (41) is (41a):

(41) The rock broke $\mathrm{T}_{\mathrm{T}}$ the window.

(41a) $\exists e\left\{\left[\right.\right.$ Breaking $_{\mathrm{T}}(e) \& \operatorname{Patient}(e$, the window $\left.)\right] \&$ $\operatorname{Agent}(e$, the rock) $\}$.

If "break ${ }_{\mathrm{T}}$ " is like "melt $\mathrm{T}_{\mathrm{T}}$ " and "move ${ }_{\mathrm{T}}$ ", there is presumably further structure, along the lines of

(41b) $\exists e\left\{\exists f\left[\operatorname{Breaking}_{\mathrm{I}}(f) \& \operatorname{Culminates}(f, e) \& \operatorname{Patient}(f\right.\right.$, the window $\left.)\right]$ $\& \operatorname{Agent}(e$, the rock $)\}$.

Assuming that the logical form of (42) is given in (42a)

(42) The window broke

(42a) $\exists f\left[\right.$ Breaking $_{\mathrm{I}}(f) \& \operatorname{Patient}(f$, the window) $]$

we have an explanation of why (41) entails (42). But this analysis raises two related questions.

Perhaps we can imagine situations, or at least understand stories, in which rocks break $\mathrm{T}_{\mathrm{T}}$ windows by hurling themselves up from the ground. But (41) can be true in mundane scenarios where the rock does not act. The rock may simply move (due to a strong wind) along a path that passes

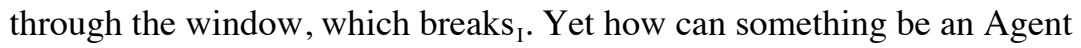
without acting? This is ruled out by the schema: $\operatorname{Agent}(e, N)$ iff $\exists a[\operatorname{action}(a, N) \&$ grounds $(a, e)]$. Moreover, my whole account has been 
based on the idea that verbs like "move ${ }_{\mathrm{T}}$ " are true of complex events, that is, events grounded by actions. Even if "Agent" is redefined so that a rock can be an Agent of some events, how can a non-actor be the Agent of a breaking $_{\mathrm{T}}$ ? If (41) is true, so is (42); hence, there is a breaking ${ }_{\mathrm{I}}$ of the window. But how can there be a breaking ${ }_{\mathrm{T}}$ of the window, on my view, if no action grounds a complex event that culminates in the breaking ? Y Yet without a breaking $_{\mathrm{T}}$ of the window, (41a) is false, whether or not rocks can be Agents.

Thus, the questions raised by (41) cannot be avoided just by saying that its logical form is

(410) $\exists e\left\{\left[\right.\right.$ Breaking $_{\mathrm{T}}(e) \& \operatorname{Patient}(e$, the window $\left.)\right] \& \theta(e$, the rock $\left.)\right\}$

where $\theta$ is some thematic role with no implication of agency. Similar questions arise with respect to

(43) Nora broke $_{\mathrm{T}}$ the window

as used in contexts where no action of Nora's caused the breaking of the window. Suppose Nora was holding a stick when a loud noise startled her, with the result that the stick passed through the window. If someone asks what happened, (43) might be a correct (if potentially misleading) reply, even though Nora performed no action that grounded an event culminating in the breaking ${ }_{\mathrm{I}}$ of the window. ${ }^{23}$ One might say that (43) is semantically ambiguous, having one reading that corresponds to (41a), and

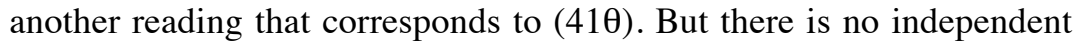
reason for thinking that (43) is lexically or syntactically ambiguous; and if possible, I want to avoid saying that a linguistic object $\Sigma$ can be associated with more than one logical form, if $\Sigma$ is unambiguous from a syntactician's point of view. If logical forms are more finely grained than syntactic structures, the mapping from syntax to logical form is non-trivial. Hence, an account would be owed of when "Nora" in (43) is associated with "Agent", and when it is associated with some other thematic role.

Moreover, Baker $(1988,1997)$ offers considerable empirical support for the Uniformity of Thematic Assignment Hypothesis (UTAH), according to which noun phrases with the same grammatical role have the same thematic role. Baker does not expressly consider sentences like (41) as a potential source of difficulty for UTAH. But I think such sentences conform to UTAH, even though "the rock" can play the same grammatical

\footnotetext{
${ }^{23}$ Such cases differ from those in which an action has unintended effects. If Nora swings a bat, forgetting about the window behind her, the breaking ${ }_{\mathrm{T}}$ is a complex event grounded by her action. See Feinberg (1965) on the "accordion effect". This effect is at best strained in cases like (41). If the breaking I $_{\text {of }}$ the window woke the baby, it seems odd to say that the rock woke the baby.
} 
role as a name for someone who acts. So I want to broaden my initial proposal about what it is to be an Agent.

5.2

A breaking ${ }_{\mathrm{T}}$ is any event that culminates in a breaking . Since every event culminates itself, every breaking is a breaking $_{\mathrm{T}}$, the extension of "break ${ }_{\mathrm{T}}$ " thus includes the extension of "break" ${ }_{\mathrm{I}}$. So not every breaking $\mathrm{T}_{\mathrm{T}}$ is grounded by an action. Earlier, this may have seemed like an insignificant technical point. But now, its importance should be clear. Setting aside (for the moment) the question of whether rocks can be Agents, there is no puzzle about the truth of:

(41a) $\exists e\left\{\left[\right.\right.$ Breaking $_{\mathrm{T}}(e) \& \operatorname{Patient}(e$, the window) $] \&$ $\operatorname{Agent}(e$, the rock $)\}$

(41b) $\exists e\left\{\exists f\left[\operatorname{Breaking}_{\mathrm{I}}(f) \& \operatorname{Culminates}(f, e) \& \operatorname{Patient}(f\right.\right.$, the window $\left.)\right]$ $\& \operatorname{Agent}(e$, the rock $)\}$.

If there is a breaking (of the window), it follows that there is a breaking $_{\mathrm{T}}$ (of the window).

This can seem like cheating. For I have stressed that actors are the Agents of complex events, in order to account for adjuncts. In dealing with

(32) Nora melted T $_{\mathrm{T}}$ the chocolate with her lens.

I said that the melting ${ }_{\mathrm{T}}$ was a complex event distinct from any melting ${ }_{\mathrm{I}}$. In this case, the relevant melting ${ }_{\mathrm{T}}$ is a complex event. If (32) is true, there is a melting $_{\mathrm{I}}$ of the chocolate, and this melting is also a melting $_{\mathrm{T}}$. But this second melting $_{\mathrm{T}}$ is not With-her-lens, nor is Nora the Agent of it; these are properties of the melting ${ }_{\mathrm{T}}$ described in (32). With respect to (41), though, no action grounds any complex event. The only breaking ${ }_{\mathrm{T}}$ is the breaking . Thus, if (41) is true $\exists e\left\{\exists f\left[\operatorname{Breaking}_{\mathrm{I}}(f) \&(e=f) \& \operatorname{Patient}(f\right.\right.$, the window)] $\& \operatorname{Agent}(e$, the rock $)\}$; though I do not think this is the logical form of (41).

If every breaking is a breaking $_{\mathrm{T}}$ (but not conversely), this also points us towards an answer to our other question: how can a rock be the Agent of a breaking ${ }_{\mathrm{T}}$ ? We must define "Agent", so that a rock can be the Agent of a breaking ${ }_{\mathrm{I}}$. Suppose there are indeed two importantly different kinds of breakings $_{\mathrm{T}}$ : simple ones (i.e. breakings $\mathrm{s}_{\mathrm{I}}$ ) and complex ones (i.e. events that begin with an action and end with a breaking $\mathrm{I}_{\mathrm{I}}$. Then perhaps there are two importantly different ways of being the Agent of a breaking . $_{\text {. }}$.

To be the Agent of a complex breaking ${ }_{\mathrm{T}}$ is to perform the action that grounds it. But a simple breaking ${ }_{\mathrm{T}}$ is not grounded by any action. So let us say that the Agent of a breaking ${ }_{\mathrm{I}}$ is the salient initiator of the event. Indeed, let us say that in general, the Agent of event $e$ is the salient initiator of $e$; where performing an action that grounds a complex event is the para- 
digmatic case of initiating an event. One might view this suggestion as a version of Dowty's (1979) proposal that "Agent" is a prototype notion. On Dowty's view, which Baker (1997) endorses, the Agent of $e$ is the event participant most like an actor: if Nora acts in $e$, Nora is the Agent of $e$; but if no action is performed in $e$, there can still be an Agent of $e$, if some participant in $e$ (say, a moving rock) is enough like an actor. Similarly, on my view: if a given breaking ${ }_{\mathrm{T}}$ is complex, its Agent is the actor whose action

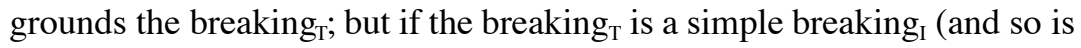
not grounded by an action), its Agent is the event participant most like an actor, in that this event participant counts as the salient (though non-acting) initiator of the breaking . The idea is that something can be like an actor, by participating in an event that causes some indicated event; and the rock participates in an event (its motion) that causes the breaking ${ }_{\mathrm{T}} /$ breaking ${ }_{\mathrm{I}}{ }^{24}$

While sketchy, these remarks about the extension of "Agent" can be extended to cases that otherwise seem puzzling. If a rock can be the Agent of a breaking, it is not hard to see how a kettle can be the Agent of a whistling. So the logical forms of (44-45) can be as indicated:

(44) The kettle whistled.

(44a) $\exists e[$ Whistling(e) \& $\operatorname{Agent}(e$, the kettle)].

(45) Nora whistled.

(45a) $\exists e[$ Whistling(e) \& Agent $(e$, Nora)].

In each case, the grammatical subject (the kettle/Nora) is the salient initiator of the whistling. But while Nora performs an action that grounds a complex event culminating with some air passing through Nora's mouth, the kettle performs no action. Still, the kettle is like Nora: a change in the kettle causes a sound when steam passes through the relevant aperture. In this sense, the kettle is more like Nora than the rock, whose motion is not internally generated. So one can draw distinctions among non-acting Agents. Indeed, one might take the kettle's whistling to be a complex event grounded by a (nonintentional) change in the kettle, and culminating with the resulting sound. If there is such an event, one might define a notion "action*" that includes both tryings and the grounders of (complex) events like the kettle's whistling. (It is not obvious, though, that the

${ }^{24}$ My claim is that UTAH is compatible with (41), not that relaxing the notion of "Agent" avoids every objection to UTAH. (See Pesetsky 1995, Baker 1997.) Nor have I said what makes something the Agent of an event not grounded by an action. There is an analog of the Euthyphro problem: is a participant $\Pi$ in event $e$ represented as the grammatical subject of a true sentence about $e$, because $\Pi$ is the salient initiator of $e$; or is $\Pi$ the salient initiator of $e$, because $\Pi$ is represented as the grammatical subject (of a true sentence about $e$, and) UTAH governs the mapping from grammatical to thematic roles? I have nothing useful to say on this score; though my hunch is that neither "because"-claim will be satisfactory. 
whistlings of kettles are complex events. It is hard to find semantic/spatiotemporal arguments as persuasive as those that apply to pullings and shootings.)

Similar remarks apply to "The dog walked". Those inclined to think that animals act may see no problem in saying that a dog can be the Agent of a walking. But consider

(46) Nora walked ${ }_{T}$ the dog, so (47) the dog walked $_{\mathrm{I}}$.

The compellingness of this inference is explained, if its logical form is

$\exists e\left\{\exists f\left[\right.\right.$ Walking $_{\mathrm{I}}(f) \&$ Culminates $(f, e) \& \operatorname{Patient}(f$, the $\left.\operatorname{dog})\right] \&$ $\operatorname{Agent}(e$, Nora $)\}$, so $\exists f\left[W_{\text {Walking }}(f) \& \operatorname{Patient}(f\right.$, the dog $\left.)\right]$.

Here the dog is represented as the Patient of the walking ${ }_{\mathrm{T}}$ and the walking ${ }_{\mathrm{I}}$. This is not implausible; for if the dog is $\operatorname{walked}_{\mathrm{T}}$, then arguably, it is not a genuine actor. Given UTAH, though, one might expect the logical form of (47) to be

(47a) $\exists f\left[\right.$ Walking $_{\mathrm{I}}(f) \& \operatorname{Agent}(f$, the dog) $]$

with the dog represented as the Agent of the walking ${ }^{25}$ This conforms to the intuition that (47) is often true in situations where the dog walks on its own (i.e. when it is not walked $_{\mathrm{T}}$ ); and if (46) is true, the non-acting dog can be the Agent of the walking , while Nora is the Agent of the walking . $_{\text {. }}$ The dog would be the Agent and Patient of the walking; but something can be the Agent and Patient of an event, as when Nora washes herself. If (47a) is the logical form of (47), however, the inference from (46) to (47) is not strictly valid. Still, the inference is good, given that a dog who is the Patient of a walking is the Agent of the walking. Perhaps this is why the inference feels compelling, though a little strange.

Kettles and dogs may shed light on cases in which a person "instinctively" ducks or "mindlessly" drums her fingers. Earlier, I described these as non-paradigmatic actions (not plausibly identified with tryings), and set them aside as special cases. But if a notion of "action*" can include the whistling of a kettle, or the walking ${ }_{\mathrm{I}}$ of a dog walked $_{\mathrm{T}}$, duckings and drummings may be actions*. At any rate, one can begin to see how Nora could be the Agent of such events without there being any trying that is her action of ducking or drumming. Moreover, if "Agent" means salient initiator, we can say that a person is the Agent of her tryings - even though a person's relation to her tryings differs from her relation to the complex events of which she is the Agent. Nora initiates the lifting of a rock in virtue of performing an action distinct from (though a part of) the lifting; Nora tries to lift the rock. But Nora does not initiate her trying in virtue of

${ }^{25}$ If (47) is the result of movement from an underlying structure, where "the dog" is the object of "walked,", then (47) presents no real difficulty for UTAH. (Cf. "the window broke."; and see note 10.) 
performing an action distinct from the trying. Nora is the Agent of her tryings, simply because they are hers; Nora's tryings stem from her reasons. Initially, it may have seemed odd to say that Nora is the Agent of both complex events grounded by tryings and the tryings themselves. But if there is more than one way to be a salient initiator, we should expect a certain diversity amongst the events of which a person is the Agent.

\section{3}

If we allow that rocks can be Agents, and that a person can be the Agent of non-complex events, it is not a big leap to allowing that events can be (non-paradigmatic) Agents. (Cf. Parsons 1990.) Thus, one can maintain UTAH in the face of sentences like

(48) The explosion broke $\mathrm{T}_{\mathrm{T}}$ the window

without saying that the syntactic structure of (48) differs importantly from that of

(41) The rock broke T $_{\mathrm{T}}$ the window.

One can say that (48) has the logical form represented in (48a), with still further structure reflected in (48b):

(48a) $\exists e\left\{\left[\right.\right.$ Breaking $_{\mathrm{T}}(e) \& \operatorname{Patient}(e$, the window $\left.)\right] \&$ $\operatorname{Agent}(e$, the explosion $)\}$

(48b) $\exists e\left\{\exists f\left[\operatorname{Breaking}_{\mathrm{I}}(f) \& \operatorname{Culminates}(f, e) \& \operatorname{Patient}(f\right.\right.$, the window $\left.)\right]$ $\& \operatorname{Agent}(e$, the explosion $)\}$.

There are two possibilities concerning the " $e$-position" event and the explosion's relation to it. The breaking ${ }_{\mathrm{T}}$ could be simple $(e=f)$ or complex $(e \neq f)$. In the first case, the explosion is the salient initiator of a breaking that is a breaking ; and the explosion initiates the breaking ${ }_{\mathrm{I}}$ by virtue of causing it. In the second case, the explosion is the salient initiator of a complex event that culminates with a breaking; and the explosion initiates the complex breaking $\mathrm{T}_{\mathrm{T}}$ by virtue of grounding it. (Either way, if Mary's singing broke $\mathrm{T}_{\mathrm{T}}$ the window, Mary's action caused the breaking ${ }_{\mathrm{I}}$ and grounded the breaking ${ }_{\mathrm{T}}$; so Mary broke $\mathrm{T}_{\mathrm{T}}$ the window.)

One might think this maneuvering trivializes UTAH. Instead of saying that sentences of the form "_ broke $_{\mathrm{T}}$ the window" have different logical forms, depending on whether the subject plays the role of Agent (or another thematic role with no implication of agency), I have said that there are many ways to be an Agent. Perhaps this a kind of ambiguity; for there are important differences between rocks, kettles, and paradigmatic actors. But thinkers can notice differences not marked by the language itself. We know that rocks and explosions are not actors; but I don't think we know this simply by virtue of knowing a natural language. Correspondingly, I doubt that "Nora broke $\mathrm{T}_{\mathrm{T}}$ the window" and "The rock broke $\mathrm{T}_{\mathrm{T}}$ the window" have different entailments with respect to who or what acted. (Again, we 
can understand stories in which rocks act; and Nora can break $\mathrm{T}_{\mathrm{T}}$ the window without acting.)

Moreover, it is not arbitrary to group explosions and rocks that break windows together with persons who try to break $\mathrm{k}_{\mathrm{T}}$ windows and succeed.

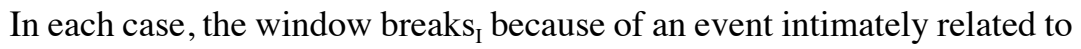
the relevant Agent/subject. Those who try are the paradigmatic (but not the only) Agents ${ }^{26}$ So returning to an issue earlier set aside, it seems that the logical form of "Booth shot Lincoln" is (16), with (16*) reflecting the further claim that Booth is a paradigmatic Agent:

(16) $\exists e[\operatorname{Shooting}(e) \& \operatorname{Agent}(e, \operatorname{Booth}) \& \operatorname{Patient}(e, \operatorname{Lincoln})]$

(16*) $\exists e\{\operatorname{Shooting}(e) \& \exists a[\operatorname{action}(a$, Booth $) \&$ grounds $(a, e] \&$ Patient $(e$, Lincoln $)\}$.

In this sense, the ambiguity I have discussed is not purely semantic; though perhaps the meanings of event sortals like "shoot" guarantee that such sortals apply only to events grounded in actions. (Arguably, all killings are grounded in actions.) In any case, the main point is that we can use event descriptions like "the shooting of Lincoln" in referring to the (complex) shooting, or the action/trying that grounds it. ${ }^{27}$

Department of Philosophy

PAUL M. PIETROSKI

McGill University

855 Sherbrooke West

Montreal, H3A $2 T 7$

Canada

\section{REFERENCES}

Baker, M. 1988: Incorporation. Chicago: University of Chicago Press.

-1997: "Thematic Roles and Syntactic Structure", in L. Haegeman (ed.) Elements of Grammar, Dordrecht: Kluwer, pp. 73-137.

Belletti, A. 1988: "The Case of Unaccusatives". Linguistic Inquiry, 19, pp. 1-34.

Bennett, J. 1988: Events and Their Names. Indianapolis: Hackett.

Burzio, L. 1986: Italian Syntax. Dordrecht: Reidel.

Chomsky, N. 1995: The Minimalist Program. Cambridge, MA: MIT Press.

${ }^{26}$ It is tempting to reply that "Agent" really means causer, not initiator; but this would lead back to the pure causative analysis discussed above. For better or worse, it seems that the paradigmatic Agentive relation holds between actors and events grounded by their actions.

${ }^{27}$ My thanks to: Mark Baker, Susan Dwyer, Richard Larson, Ernie Lepore, a referee for Mind, audiences at the Universities of North Carolina and Maryland, the (FCAR funded) mind-language group at McGill - and Judith Thomson, for influence extending beyond that indicated by citations to her written work. 
Davidson, D. 1967: “The Logical Form of Action Sentences" in N. Rescher (ed.) The Logic of Decision and Action, Pittsburgh: University of Pittsburgh Press, pp. 188-221.

-1971: "Agency", in R. Binkley et al. (eds.) Agent, Action, and Reason, Dordrecht: Kluwer.

Dowty, D. 1979: Word Meaning and Montague Grammar. Boston: Reidel.

Dretske, F. 1988: Explaining Behavior. Cambridge, MA: MIT Press.

Feinberg, J. 1965: “Action and Responsibility”, in M. Black (ed.) Philosophy in America, Ithaca, NY: Cornell University Press, pp. 134-57.

Frankfurt, H. 1988: The Importance of What We Care About. Cambridge: Cambridge University Press.

Haegeman, L. 1994: Introduction to Government \& Binding Theory, 2nd Edition. Cambridge, MA: Blackwell.

Hart, H. and Honoré, A. 1959: Causation and the Law. Oxford: Oxford University Press.

Herburger, E. 1997: In the Event of Focus. Doctoral Dissertation, University of Southern California.

Higginbotham, J. 1983: "The Logical form of Perceptual Reports". Journal of Philosophy, 80, pp. 100-27.

Hornsby, J. 1980: Actions. London: Routledge and Kegan Paul.

Lombard, L. 1986: "How not to Flip the Prowler", in E. LePore and B. McLaughlin (eds.) Actions and Events: Perspectives on the Philosophy of Donald Davidson, Oxford: Blackwell, pp. 268-81.

McGinn, C. 1982: The Character of Mind. Oxford: Oxford University Press.

O'Shaughnessy, B. 1973: “Trying as the Mental 'Pineal Gland”. Journal of Philosophy, 71, pp. 365-86.

1980: The Will. Cambridge: Cambridge University Press.

Parsons, T. 1990: Events in the Semantics of English. Cambridge, MA: MIT Press.

Pesetsky, D. 1995: Zero Syntax. Cambridge, MA: MIT Press.

Schein, B. 1993: Plurals. Cambridge, MA: MIT Press.

Sellars, W. 1956: "Empiricism and the Philosophy of Mind", in H. Feigl and M. Scriven (eds.) Minnesota Studies in the Philosophy of Science, Vol. 1, Minneapolis: University of Minnesota Press, pp. 253-329.

Taylor, B. 1984: Modes of Occurrence. Oxford: Blackwell.

Thomson, J. 1971: "The Time of a Killing". Journal of Philosophy, 68, pp. 115-32.

Vendler, Z. 1967: Linguistics in Philosophy. Ithaca, NY: Cornell University Press. 
Actions, Adjuncts, and Agency 111

Vlach, F. 1983: “On Situation Semantics for Perception”. Synthese, 54, pp. 129-52. 
112 Paul M. Pietroski 